\title{
Instrumental and Pavlovian Mechanisms in Alcohol Use Disorder
}

\author{
Nuria Doñamayor ${ }^{1} \cdot$ Claudia Ebrahimi $^{1}$ - Maria Garbusow ${ }^{1} \cdot$ Friederike Wedemeyer $^{1}$. Florian Schlagenhauf ${ }^{1}$. \\ Andreas Heinz ${ }^{1}$
}

Accepted: 16 September 2020 / Published online: 19 October 2020

(C) The Author(s) 2020

\begin{abstract}
Purpose of Review Current theories of alcohol use disorders (AUD) highlight the importance of Pavlovian and instrumental learning processes mainly based on preclinical animal studies. Here, we summarize available evidence for alterations of those processes in human participants with AUD with a focus on habitual versus goal-directed instrumental learning, Pavlovian conditioning, and Pavlovian-to-instrumental transfer (PIT) paradigms.

Recent Findings The balance between habitual and goal-directed control in AUD participants has been studied using outcome devaluation or sequential decision-making procedures, which have found some evidence of reduced goal-directed/model-based control, but little evidence for stronger habitual responding. The employed Pavlovian learning and PIT paradigms have shown considerable differences regarding experimental procedures, e.g., alcohol-related or conventional reinforcers or stimuli.

Summary While studies of basic learning processes in human participants with AUD support a role of Pavlovian and instrumental learning mechanisms in the development and maintenance of drug addiction, current studies are characterized by large variability regarding methodology, sample characteristics, and results, and translation from animal paradigms to human research remains challenging. Longitudinal approaches with reliable and ecologically valid paradigms of Pavlovian and instrumental processes, including alcohol-related cues and outcomes, are warranted and should be combined with state-of-the-art imaging techniques, computational approaches, and ecological momentary assessment methods.
\end{abstract}

Keywords Alcohol use disorder · Habits · Goal-directed control · Pavlovian conditioning · Pavlovian-to-instrumental transfer · Humans

\section{Introduction}

Drug addiction has been characterized in terms of the brain's learning and memory systems. This view posits a gradual shift from initial voluntary drug use to an increasing loss of control over drug intake, which becomes habitual or even compulsive drug addiction [1-4]. Drug use starts out as a goal-directed behavior, mediated by the reinforcing and hedonic effects of the drug, but habitual processes eventually take over, hampering attempts to stop drug intake, in spite of severely aversive

This article is part of the Topical Collection on Alcohol Addiction

Nuria Doñamayor

nuria.donamayor@charite.de

1 Department of Psychiatry and Psychotherapy, Charité Campus Mitte, Charité - Universitätsmedizin Berlin, corporate member of Freie Universität Berlin, Humboldt-Universität zu Berlin, and Berlin Institute of Health, Charitéplatz 1, Berlin 10117, Germany consequences and conscious decisions to reduce consumption or to remain abstinent. This transition is considered to depend upon interactions between Pavlovian and instrumental learning processes $[1,3]$. Habitual or even compulsive instrumental drug-taking behaviors are thought to be triggered by internal and external drug-associated cues, acute stress events or a priming drug dose [5], as well as by internal mood states [6]. In chronic drug users, conditioned drug cues may gain incentive salience through Pavlovian mechanisms, whereas alternative reinforcers lose relevance [7, 8]. Addictive behavior is also characterized by negative reinforcement during withdrawal distress and early abstinence, which is defined as drug taking that alleviates a distress-associated aversive emotional state [9]. In the current review, we focus on the empirical evidence regarding these processes and the hypothetically underlying learning mechanisms in the development and maintenance of alcohol use disorder (AUD). For each process, we first briefly report the available behavioral paradigms and underlying neural structures, and then summarize the studies assessing participants with AUD and at-risk groups. 


\section{Instrumental Learning: Habitual Versus Goal-Directed Behavior}

\section{Behavioral Paradigms and Neural Circuitry}

Instrumental learning can be controlled by both goal-directed and habitual processes $[10,11]$. Under habitual control, action selection is driven by rather rigid stimulus-response (S-R) associations and led by past reinforcement [12]. Under the more computationally costly goal-directed control, the subject uses their knowledge about the response-outcome (R-O) contingency and the current incentive value of the outcome to guide behavior [10,13, 14]. Goal-directed and habitual behaviors differ therefore in their sensitivity to changes in both the causal nature of the instrumental R-O relationship and the current value of the outcome $[11,15]$, with insensitivity to such changes considered a hallmark of habitual behavior [16].

Classically, sensitivity to changes in outcome value can be assessed through outcome devaluation. Briefly, these tasks consist of an instrumental learning stage, in which an action is paired with a desired outcome, followed by an outcome devaluation phase, e.g., through sensory-specific satiation, aversive conditioning or instruction, and a test done in extinction. On the other hand, sensitivity to changes in the causal R$\mathrm{O}$ relationship can be assessed with contingency degradation tasks, in which the probabilities of receiving action-contingent outcomes and non-contingent outcomes are manipulated, so that the causal R-O relationship is degraded by increasing the latter. When both probabilities are equal, performing the action has no effect on the likelihood of the outcome, so that the net R-O contingency, and thus the causal status of the action, is zero $[10,17]$. It has been extensively demonstrated that both animals and humans are sensitive to changes in outcome value, as reflected by decreased responding to devalued outcomes $[10,18-21]$, as well as to contingency degradation, with decreased responding to smaller R-O contingencies and, in humans, explicit judgments about the causal relationship between action and outcome that closely approximate instrumental behavior [10, 17, 22-25]. Indeed, outcome devaluation procedures are currently considered the strongest test of habitual behavior [26].

More recently, computational reinforcement learning theories have formalized habitual and goal-directed processes in terms of model-free (habitual) and model-based (goaldirected) control $[13,27]$. This framework uses sequential Markov decision tasks, such as the so-called two-step task [28]. In this task, participants must perform two consecutive choices to obtain a reward: first-stage stimuli lead to different second-stage states with fixed probabilities, and second-stage stimuli are associated with slowly changing reward probabilities. While a model-free agent will repeat previously rewarded actions, a model-based agent will take both previous reward and the task's transition structure into account. In the computational model, first-stage actions are computed according to both model-free temporal-difference learning and model-based reinforcement learning algorithms, which are typically weighted with a free parameter $\omega$, with $\omega=1$ indicating pure model-based and $\omega=0$ pure model-free control. Performance of clinically healthy humans in the two-step task is consistent with a mixture of model-free and model-based behavior [28-32]. This task has been recently back-translated to animal research, showing a similar behavioral pattern in rodents [33-35]. Moreover, a recent study has shown that rodents initially only use outcomes to drive behavior, but recover the structure of the environment over the course of learning and also use it to make decisions [36]. Indeed, some studies suggest that both rodents and humans can display predominantly model-based behavior following overtraining in the two-step task [37, 38].

In animals, there is solid evidence pertaining the involvement of the orbitofrontal cortex (OFC), prelimbic prefrontal cortex (PFC), and dorsomedial striatum (DMS) in goaldirected behavior, and the infralimbic PFC and dorsolateral striatum (DLS) in habitual behavior. Lesioning the OFC has been shown to reduce $[39,40]$ and stimulating to enhance [41] goal-directed behavior in outcome devaluation tasks. OFCamygdala [42] and OFC-striatum [43] disconnection has been shown to decrease sensitivity to outcome devaluation. Similarly, reversible inactivation of the OFC also impairs model-based choices in two-step tasks [37]. Prelimbic lesions have been shown to impair sensitivity to both outcome devaluation [10, 44-46] and contingency degradation [10, 45, 47] in rodents. In contrast, infralimbic lesions result in marked sensitivity to outcome value [46]. Similarly, DMS lesions abolish sensitivity to outcome devaluation and contingency degradation [48], whereas DLS lesions increase sensitivity to outcome value $[21,49]$. Rodent research has also pointed to a role of basolateral amygdala [40], dorsal hippocampus [37], and anterior cingulate cortex (ACC) [33] in goal-directed/model-based control. Although ventromedial PFC (vmPFC) and subgenual ACC have been suggested as homologous to the rodent prelimbic [11] and infralimbic PFC [50], respectively, and anterior caudate and posterior putamen as homologous to the rodent DMS and DLS, respectively [11], the clear dissociations observed in rodents are yet to be replicated in humans.

In humans, medial OFC (mOFC) and vmPFC have been highlighted as key regions driving goal-directed behavior in outcome devaluation tasks $[19,51,52]$, with white matter tract integrity between caudate and vmPFC predicting goaldirected behavior, as reflected by increased sensitivity to instructed devaluation [52]. In contrast, devaluation insensitivity has been associated with increased subgenual ACC and ventral striatal (VS) blood-oxygen-level-dependent (BOLD) responses during S-R compared with R-O learning [50]. However, although vmPFC has been suggested to encode 
the probability of action-contingent outcomes [17, 53], recent studies have found $\mathrm{vmPFC}$ lesioned patients to be insensitive to outcome devaluation but not to contingency degradation $[54,55]$. With the two-step task, model-free and modelbased valuations consistently display overlapping neural signatures implicating both vmPFC and VS [28, 30, 31]. Some studies have implicated brain structures beyond medial prefrontal and striatal regions, suggesting that inferior frontal gyrus, dorsolateral PFC, hippocampus, and inferior parietal lobule might also be crucial for goal-directed/model-based control $[17,50,56-59]$.

\section{Findings in Alcohol Use Disorder and At-Risk Populations}

In a seminal study, Dickinson et al. [60] posited alcohol seeking as an S-R habit, by demonstrating that, in contrast to lever pressing for food pellets, lever pressing to ethanol was insensitive to devaluation in rodents. Moreover, after an extended period of self-administration, alcohol consumption will continue even if mixed with aversive quinine concentrations [61, 62]. Subsequent studies have shown that chronic intermittent ethanol exposure results in habitual alcohol seeking in rodents, as assessed with both outcome devaluation [63, 64] and contingency degradation [65] procedures. Yet, alcohol further affects rodent goal-directed behavior, with acute intoxication [66], chronic ethanol exposure [67] as well as contextual conditioning to alcohol [68] decreasing sensitivity to devaluation of non-alcoholic outcomes. Interestingly, the expression of alcohol-related habits appears to be sex and age dependent. Research has shown that chromosomal male, but not female, rodents become insensitive to alcohol devaluation [69] and that male adult, but not adolescent, rodents become insensitive to contingency degradation with alcohol outcomes after overtraining [70]. A recent study showed an intriguing interaction between sex and age at alcohol exposure. Barker et al. [71] demonstrated that exposure to alcohol during adulthood, but not during adolescence, impaired adult male rats' sensitivity to the value of sucrose solution in action-promoting reinforcement schedules. In contrast, this impairment was observed in female rats only in those exposed during adolescence, whereas those that were exposed in adulthood were sensitive to outcome devaluation in both action- and habitpromoting schedules. Dovetailing with the lesion results described above, operant responding for alcohol in rodents is initially goal-directed and driven by the DMS, which exhibits increased firing following alcohol reinforcement [21, 72]. In contrast, the DLS shows phasic activity time-locked to lever presses for alcohol self-administration [72], and overtraining results in a shift to DLS control and insensitivity to outcome devaluation [21]. Further studies have demonstrated how habitual alcohol seeking depends on glutamatergic inputs to the DLS and $\mathrm{D}_{2}$ receptors within the DLS, with infusion of a $\mathrm{D}_{2}$ receptor antagonist restoring sensitivity to devaluation of alcohol [73], and how chronic ethanol exposure induces longlasting changes in OFC excitability and OFC-DMS transmission that contribute to the loss of goal-directed control [67]. Indeed, treatments that decrease DLS function and/or output and that increase OFC activity have been reported to restore goal-directed behaviors [21, 67, 73].

In humans, studies investigating the relationship between AUD and the balance between goal-directed versus habitual behavior are limited (Table 1). Sjoerds et al. [74•] used an instructed outcome devaluation task [51] to assess the behavior of recently detoxified AUD participants. Although patients with AUD and healthy controls did not differ in their instrumental learning performance, AUD participants already displayed increased posterior putamen and decreased vmPFC activity during this phase. In the outcomedevaluation test, Sjoerds et al. [74•] report impaired R-O knowledge as reflected by choice behavior in AUD, with decreased activity in both $\mathrm{VmPFC}$ and anterior putamen, regions implicated in goal-directed control, and increased activity in the posterior putamen, an area critical for habit learning [11]. Moreover, the authors modified the task to include alcoholrelated pictures in addition to fruit images, but observed no differences between stimulus types, suggesting a shift toward habitual behavior in AUD that is not specific to addictionrelevant stimuli. In contrast, in a recent study, van Timmeren et al. [75] report no decreased devaluation sensitivity as marker of goal-directed control in recently detoxified AUD patients compared with healthy controls using an aversion-induced outcome devaluation task [76].

Other studies have employed the two-step task devised by Daw et al. [28]. In a group of recently detoxified abstinent AUD participants, Sebold et al. [77] reported that, although both groups displayed a mixture of model-free and modelbased choice behavior, AUD patients exhibited less modelbased control than healthy controls following non-rewards, but did not differ following rewards. However, this finding was not replicated in a subsequent study, in which AUD participants were divided into those who abstained and those who relapsed to alcohol at a follow-up assessment [78••]. Neither model-based choice behavior nor the computational parameter $\omega$ predicted group membership, but if poorer model-based control was associated with higher alcohol expectancies, patients had a higher relapse risk at follow-up. At the neural level, participants who relapsed to alcohol showed blunted mPFC activity associated with model-based control, whereas the authors found no differences between the groups for model-free learning signals. This study not only underlined the association between $\mathrm{mPFC}$ and goal-directed deficits in AUD but further suggests that decreased model-based control might predict poor treatment outcome only in combination with high alcohol expectancies. Similarly, Voon et al. [79] found no differences in $\omega$ between long-term abstinent AUD 


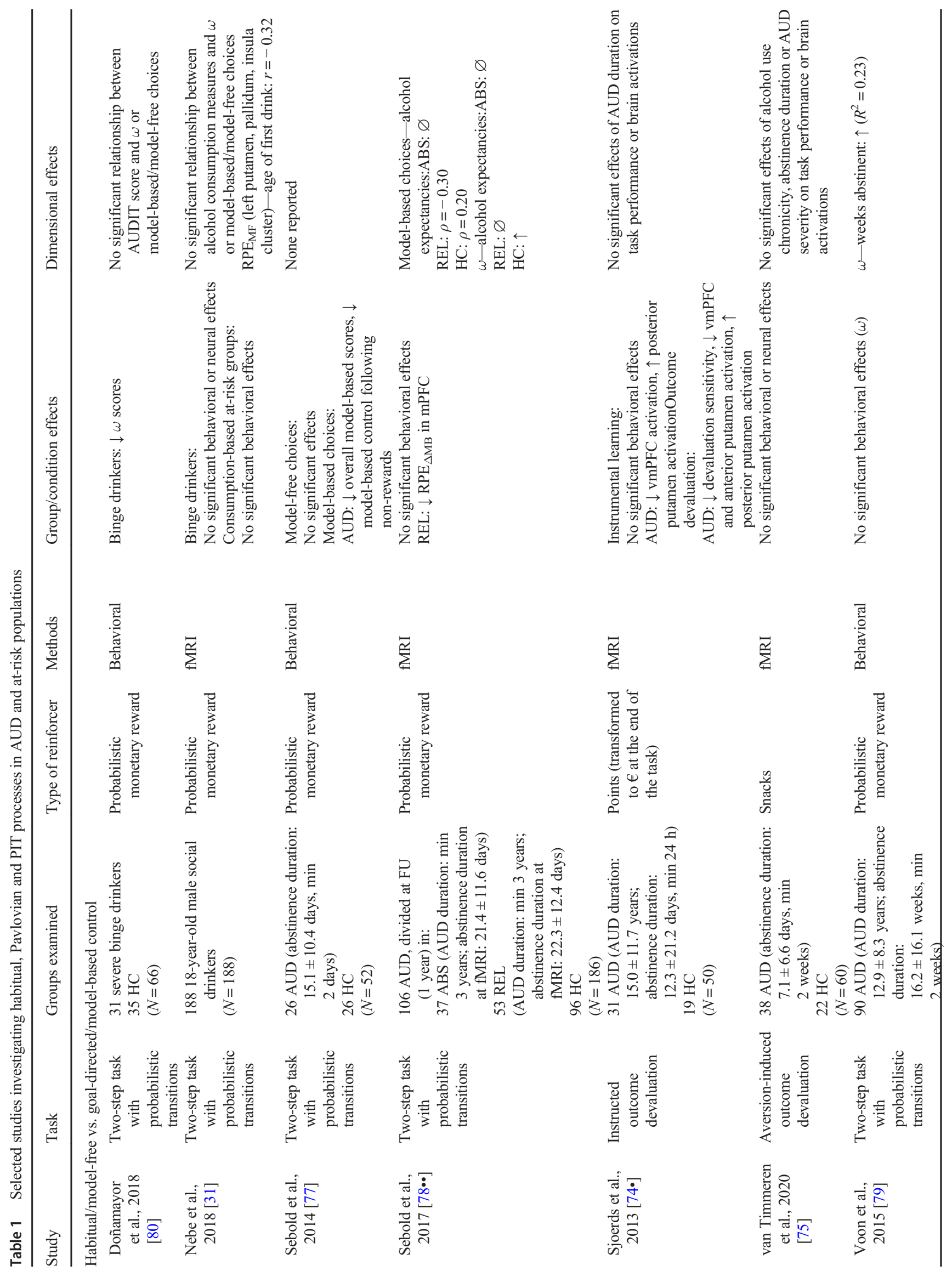




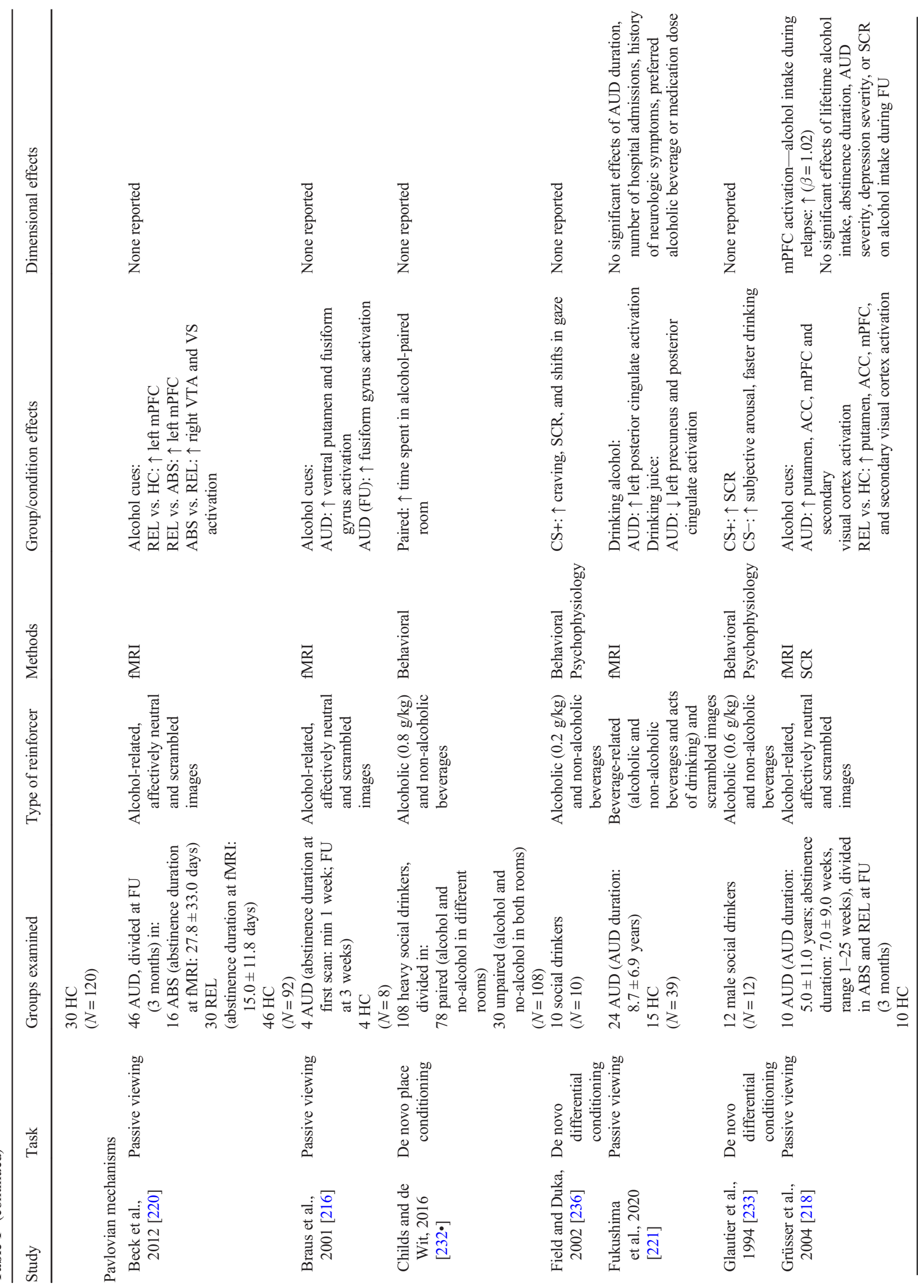




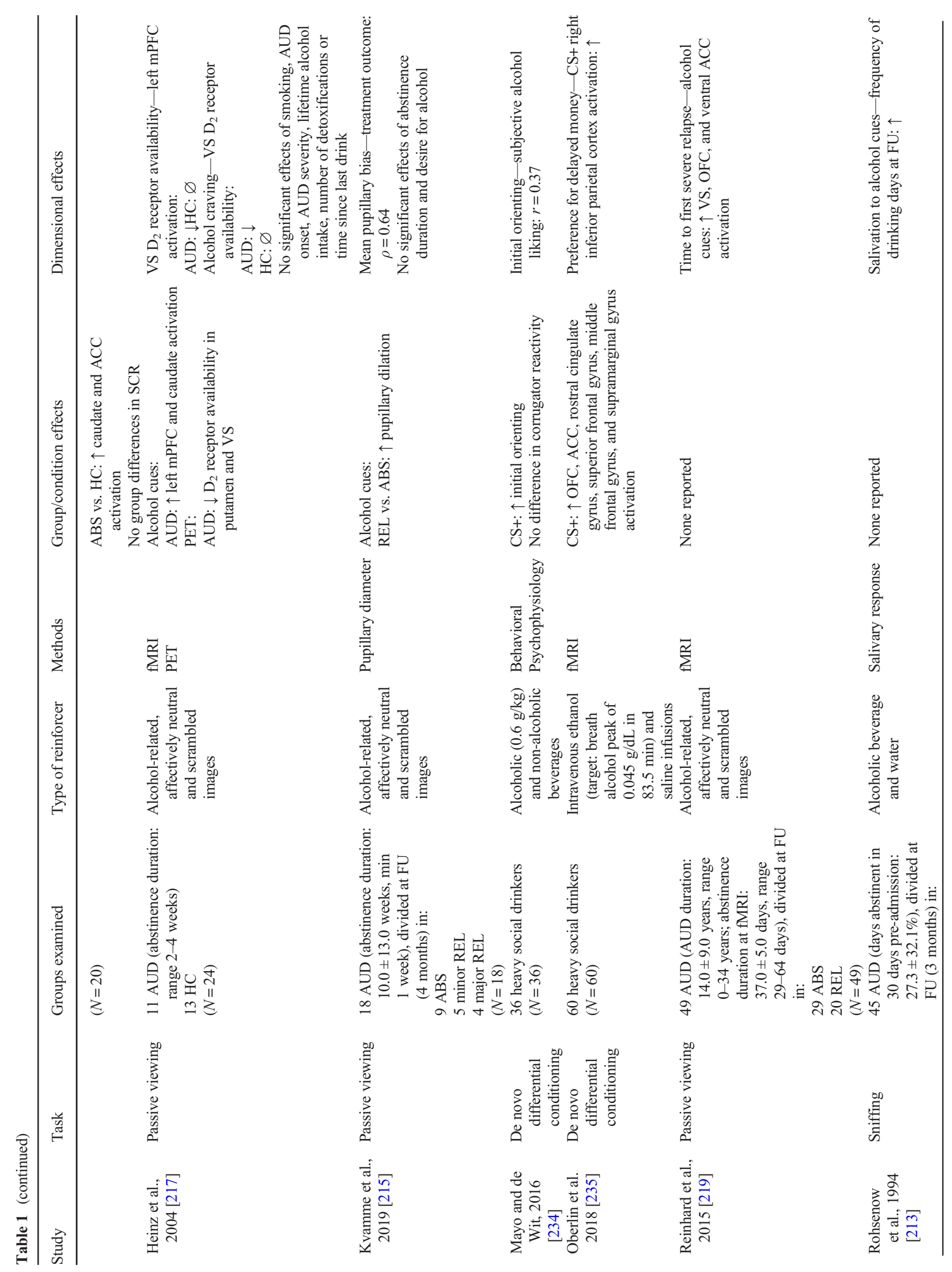




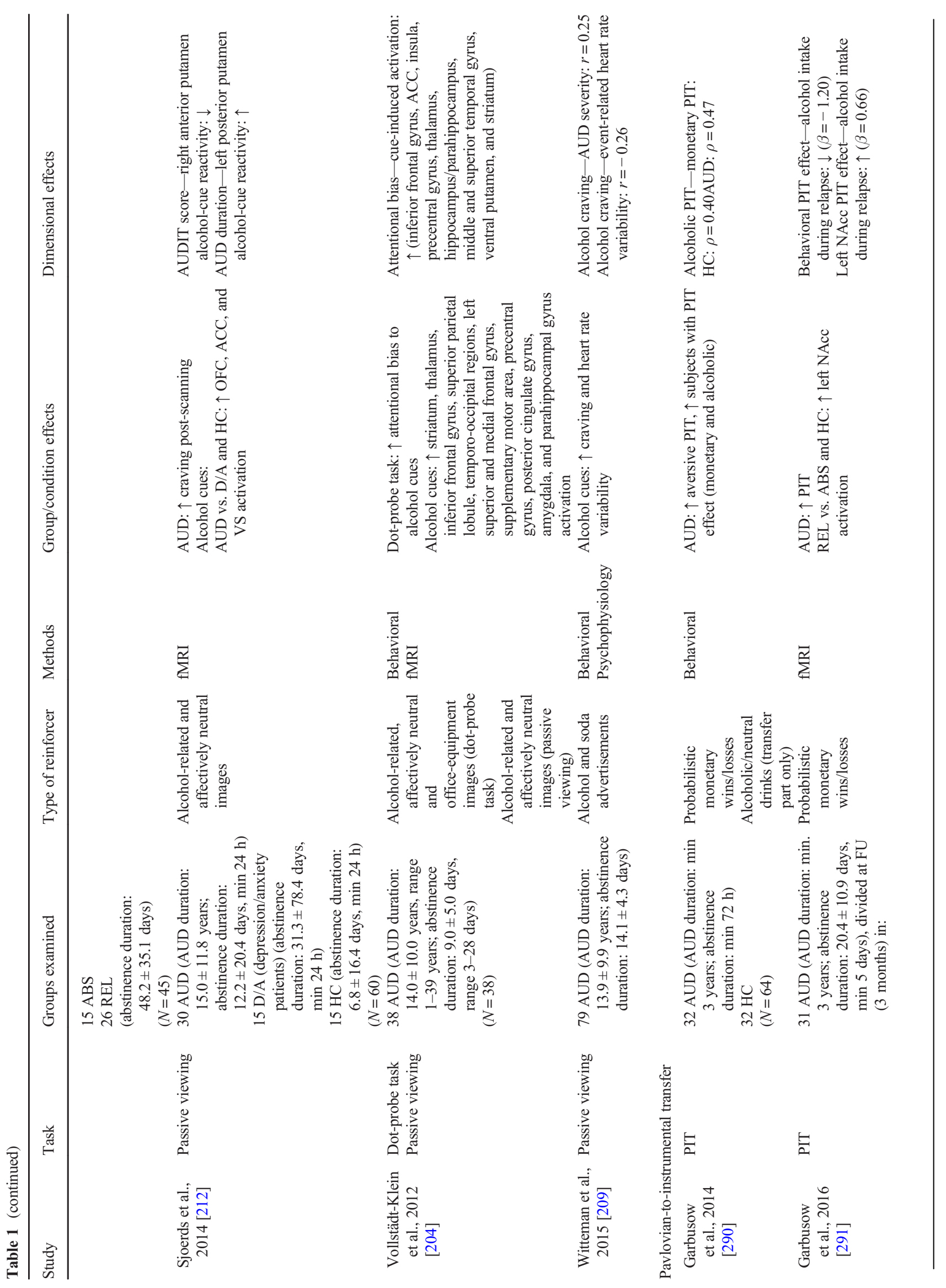




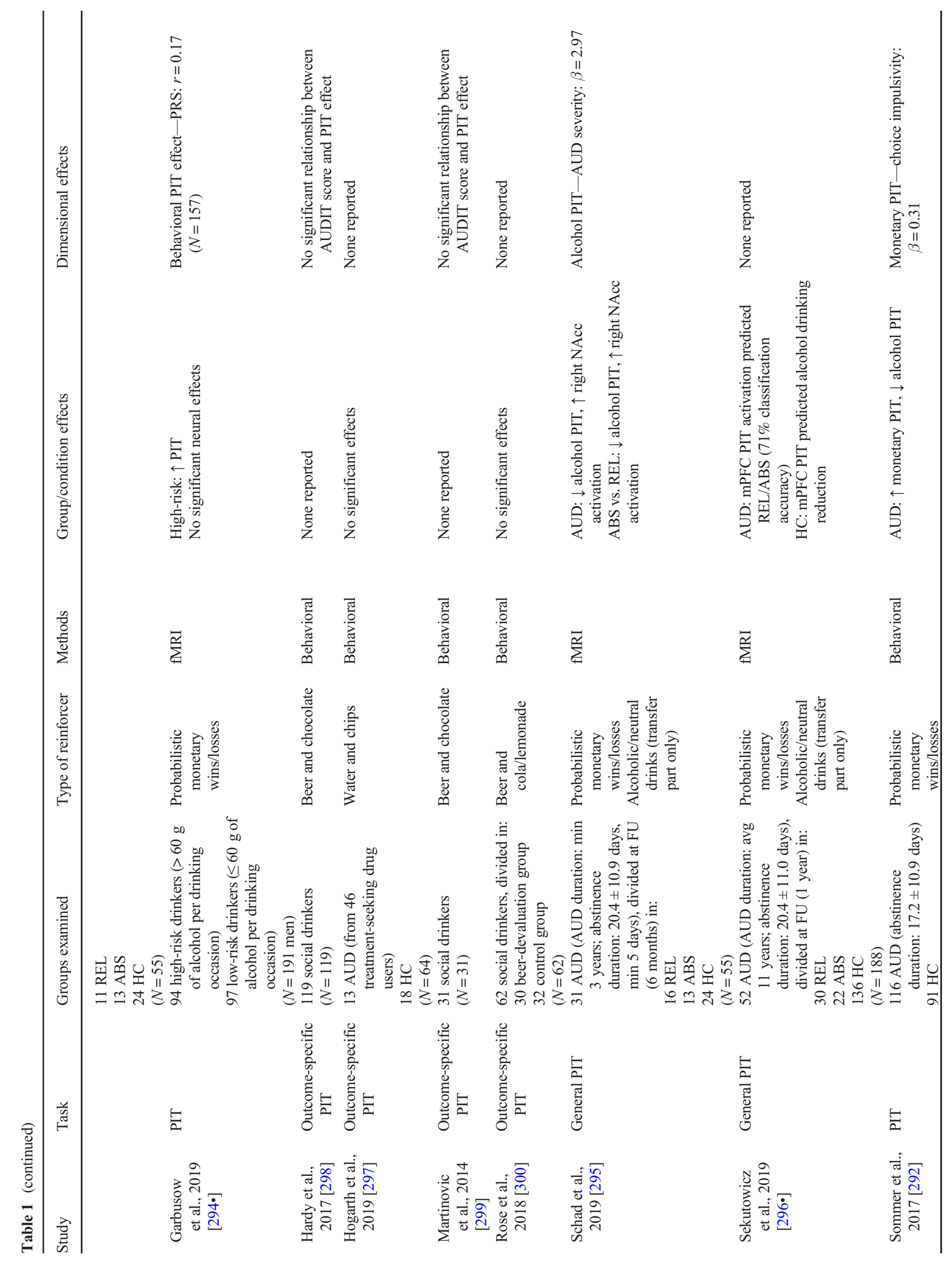




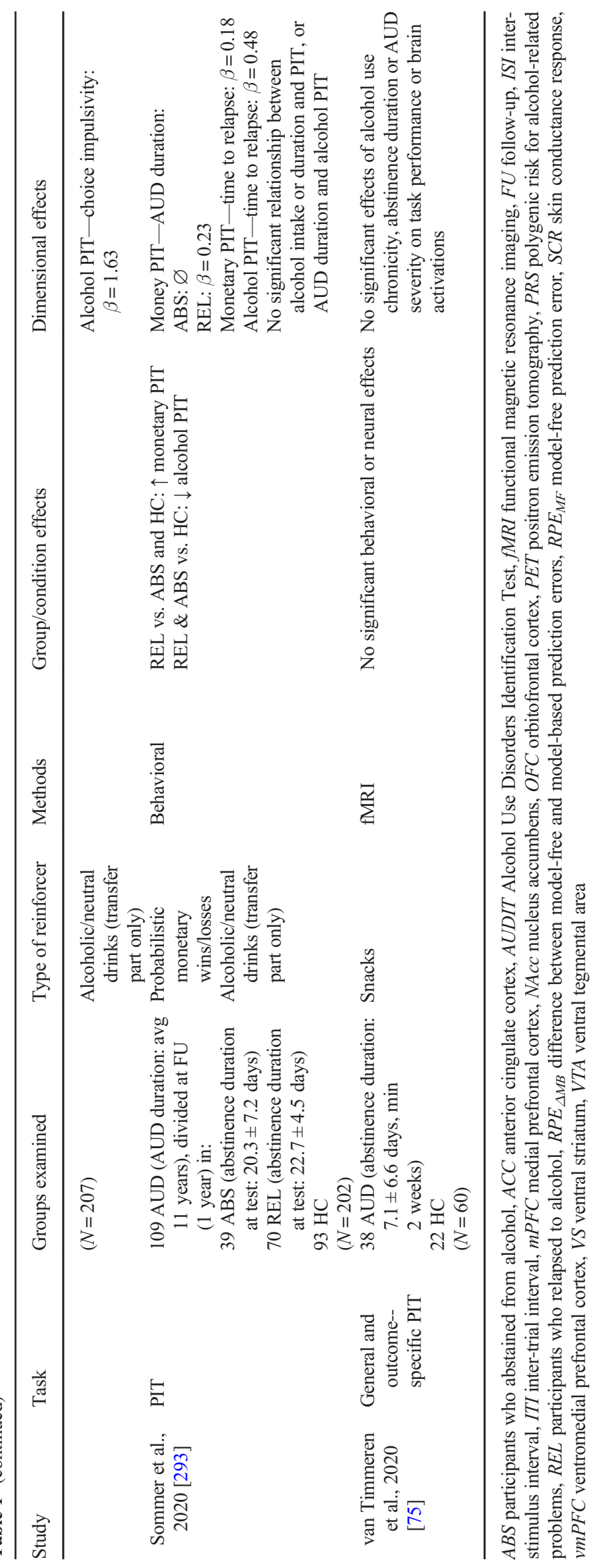


participants and healthy controls. However, they also observed that more prolonged abstinence was associated with greater $\omega$ values, indicating more model-based control and suggesting that goal-directed behaviors might improve with abstinence. Together, the studies of Sebold et al. [78••] and Voon et al. [79] indicate that model-based control may be relevant for abstinence, both as an indicator of prospective treatment outcome and for retrospective abstinence duration.

Additional studies have also investigated the relationship between alcohol use and the balance between model-free and model-based control in samples with no known diagnosis of AUD, obtaining mixed results. Greater alcohol consumption and having had binge drinking episodes were not found to be associated with model-free/model-based control in 18-yearolds [31], dovetailing with preclinical results showing that adolescent rats did not express alcohol-related habits [70]. However, severe binge drinkers, who had had at least one binging episode per week for the previous 6 months, have been reported to display reduced model-based control compared with healthy controls [80]. Two large online studies have explored the association between problematic alcohol use, assessed with the Alcohol Use Disorder Identification Test (AUDIT [81, 82]), and model-based/model-free behavior. Gillan et al. [83] reported how larger AUDIT scores were associated with decreased model-based choice behavior, as well as lower $\beta_{M B}$ scores (recent reformulations of the computational model used to analyze the two-step task no longer use the weighting parameter $\omega$ as a measure of the relative balance between model-based and model-free behavior, but rather separate inverse temperature parameters $\beta_{M B}$ and $\beta_{M F}$, which are algebraically equivalent to the original formulation under the substitution $\beta_{M B}=\omega \beta$ and $\beta_{M F}=(1-$ $\omega) \beta$ [see, e.g., 83, 84]). They further observed that this association was steeper among "putative patients" (defined as those scoring in the top 25\% on the AUDIT). Dovetailing with previous studies, model-free measures were not related to questionnaire scores. Using a deterministic two-step variant [85], however, Patzelt et al. [86] found no association between $\omega$ and AUDIT scores.

Overall, both preclinical and clinical studies have demonstrated AUD-related changes in the fronto-striatal networks that support goal-directed and habitual behavior. Studies with AUD patients suggest deficits in goal-directed or model-based action control that are, however, heavily influenced by factors such as abstinence and alcohol expectancies.

\section{Pavlovian Learning Mechanisms}

\section{Behavioral Paradigms and Neural Circuitry}

During Pavlovian conditioning, initially neutral stimuli become conditioned stimuli (CS) through repeated pairing with an unconditioned stimulus (US) [87]. As a consequence, the CS elicits a variety of conditioned responses (CRs) originally provoked by the US. Repeatedly presenting these cues in extinction, i.e., without the US, weakens CRs by establishing a new, inhibitory CS-noUS association that henceforth competes for behavioral expression with the original association [88]. This duality explains several Pavlovian relapse phenomena, where CRs recover under certain conditions [89]. In animals, the concepts of conditioned approach [90-92] and place preference [93-95] have been studied extensively in the context of addiction. In place conditioning protocols, distinct chambers (CS) are paired with the administration of either a US or noUS. In the test phase, animals are given free access to both chambers; those that develop conditioned place preference will spend more time in the US-paired context. Rewarding outcomes, including sex [96], food [97-100], fluids [100], and numerous drugs of abuse [for a review, see 95], have been shown to reliably induce conditioned place preference, which can be reinstated after extinction [95, $101]$, but can be abolished by devaluing the US [100, 102]. In Pavlovian lever autoshaping, the insertion and retraction of a lever (CS) signals food (US) delivery, irrespective of behavior. Some rats (sign-trackers) predominantly approach and interact with the Pavlovian cue, i.e., the lever, whereas others (goal-trackers) consistently approach the location of food delivery [103-106]. For sign-tracking rats, the CS appears to be attributed with incentive salience [107-109] and can even effectively reinforce new instrumental learning [107]. Following US devaluation, goal-trackers decrease both cueand outcome-directed behaviors, whereas sign-trackers continue responding to cues [110-112]. Interestingly, in contrast to instrumental devaluation studies [46, 113], sign-tracking rats become sensitive to outcome devaluation with extended autoshaping training $[110,114,115]$.

Most Pavlovian procedures used in humans were initially developed in animals. However, research attempting to translate the two paradigms and concepts described above is limited. Human studies often employ differential conditioning protocols in which one stimulus (CS+) is paired with the US while a second (CS-) is not. Both appetitive and aversive CRs have been quantified on various response systems, including subjective ratings, psychophysiological measures, and neuroimaging [116-120]. Recent research has found evidence of behaviors similar to sign- and goal-tracking in healthy participants. Using eye-tracking, Garofalo and di Pellegrino [121] and Schad et al. [122••] demonstrated that, during Pavlovian conditioning, some participants gazed more often toward the reward-predicting cues and others toward the location where money would be delivered, consistent with sign- and goal-tracking behavior, respectively. Although Pavlovian conditioning was equally successful in both groups [121], cues influenced instrumental behavior more strongly in sign-tracking individuals $[121,122 \bullet \cdot]$, consistent with animal 
findings [107]. Using a computational model, Schad et al. [122 •*] determined that goal-trackers relied strongly on model-based state prediction errors, whereas sign-trackers exhibited a neural reward prediction error signal. Attempts to closely adapt Pavlovian lever autoshaping paradigms for humans are also under way [e.g., 123; for a review, see 124]. The conditioned place preference model has also been translated to humans, frequently using virtual reality or computer avatars. These studies have demonstrated that participants show both implicit and explicit preference for rooms previously paired with primary $[125,126]$ and secondary reinforcers [127-129], as well as drugs of abuse [130, 131].

Preclinical work suggests largely overlapping neural circuits are involved in Pavlovian learning processes, including OFC [132], dorsolateral PFC [97], nucleus accumbens (NAcc) [133], subthalamic nucleus [134], amygdala [135-140], hippocampus [139], and insula [138], which are widely preserved across species [141, 142]. Recent work has shown the relevance of adrenergic, cannabinoid receptor, and NMDA signaling for Pavlovian conditioning [99, 143-146]. Still, the seminal work of Schultz et al. [147, 148] demonstrated the critical role of dopamine by showing a shift in dopaminergic firing from the US to the CS over the course of conditioning. Subsequent work has shown that phasic dopamine release in the NAcc matches reward prediction error signals in sign-tracking rats, whereas goal-tracking rats do not show a decline in US-evoked dopaminergic release despite exhibiting conditioned approach [149]. Dopamine has thus been posited a role in incentive salience attribution, not S-R learning itself [150]. A recent computational model has accounted for this individual variation in Pavlovian conditioned approach behavior and dopaminergic release patterns [151] and its predictions were supported experimentally [152]. This model accounts for the development of distinct CRs in rodents through a combination of a model-based and a featured-model-free system, a revised model-free system that uses factored representations $[151,153,154]$.

Human neuroimaging studies have repeatedly identified activity within dopaminergic midbrain, VS (including NAcc), OFC, dorsal ACC, and amygdala during appetitive Pavlovian conditioning [120, 155-162; for a meta-analysis, see 163]. In line with preclinical evidence showing that the infralimbic PFC promotes extinction recall, regulating Pavlovian relapse phenomena $[141,164]$, the vmPFC is considered particularly relevant for the recall of extinction memory, in concert with striatum and amygdala [165-168], and the inhibition of appetitive responses [117, 169]. Research further suggests that Pavlovian value signals are encoded within vmPFC and OFC $[158,170,171]$, as well as the VS [156, $160,172]$. Indeed, VS activity has been found to shift from US to CS over the course of learning [172] and to be consistent with reward prediction error signals $[162,172]$. A recent study, however, reported NAcc model-free reward prediction error activity only in those individuals classified as signtrackers [122••], dovetailing with prior animal findings [149]. A few studies have further suggested that the dorsal striatum might not only be involved in instrumental [11] but also in Pavlovian conditioning [158, 160], supporting modelbased inference, i.e., representing a cognitive map of Pavlovian contingencies even in the absence of action, as reflected by participants' explicit contingency knowledge [160]. In a similar vein, the amygdala has been found to be engaged in model-based inference during Pavlovian conditioning [173], although prediction error signals in this structure have also been reported to be stronger in sign- than goaltracking participants $[122 \cdot \bullet]$.

\section{Findings in Alcohol Use Disorder and At-Risk Populations}

Pavlovian lever autoshaping procedures have been reported to induce high volumes of ethanol drinking in rodents and have been suggested as an animal learning model of AUD [91]. Using an alcoholic US not only induces sign-tracking behavior in rats [174-176] but shifts conditioned approach behavior from goal- to sign-tracking over the course of training [177, 178], demonstrating how Pavlovian alcohol cues become powerful incentive stimuli. Moreover, sign-tracking has also been shown to enhance operant responding for alcohol [174, 179]. Importantly, exposure to alcohol during adolescence has been reported to blunt goal-tracking behavior [180] and increase sign-tracking behavior in adulthood [181, 182]. Indeed, exposure to alcohol induces changes in the dopaminergic system, with both increased phasic dopamine signaling to the CS [178] and to positive prediction errors [182]. Regarding ethanol-induced place conditioning, mice show robust conditioned place preference [183-185] (but results with rats are mixed [for a review, see 95]) that can be facilitated by stress [186-188] and is also prone to Pavlovian relapse effects like reinstatement [101, 189]. Striatal dopamine [190], cannabinoid-1 receptor [190, 191], and noradrenergic signaling [192] have been attributed a role in the acquisition of ethanol-induced conditioned place preference. Both NAcc and amygdala have been shown to be relevant for the acquisition and expression of ethanol-induced conditioned place preference $[185,193]$, with antagonism of NAcc NMDA receptors blocking conditioned place preference expression [185] and NMDA-receptor partial agonist D-cycloserine interfering with reconditioning, but having no effect on extinction [194]. Several studies have demonstrated that naloxone facilitates the extinction of ethanol-induced conditioned place preference $[189,195,196]$, even to the point of generating a weak conditioned place aversion [196], suggesting that opioid receptor activation also mediates the motivational effects of alcohol. Indeed, injections of a delta-opioid receptor antagonist in the central amygdala can reverse ethanol-induced 
conditioned place preference [197]. In a compelling design, Cunningham and Patel [198] used a modified place conditioning paradigm to assess conditioned approach by introducing a visual cue in the conditioning chamber. Here, mice showed a strong preference for the location of the visual cue that had been associated with intraperitoneal ethanol injections, a behavior consistent with sign-tracking.

Although translation of the animal concepts and methodologies described above is limited, human studies have addressed related constructs, such as cue reactivity [90, 124] (Table 1). The presentation of alcohol-associated cues, e.g., the sight or smell of an alcoholic beverage, has been shown to bias approach tendencies [199-201] and attention [202-204], with increased attentional bias predicting relapse risk [205, 206], and induce conscious craving [204, 207-212] in individuals diagnosed with AUD. Passive viewing tasks, in which participants are shown alcohol cues (images of alcoholic beverages), affectively neutral images and abstract images, have been widely used to research cue reactivity in AUD patients. These evoke a number of psychophysiological responses, including increased salivation [213], changes in heart rate variability [203, 206, 209, 214], and larger pupillary dilation [215], some of which have also been associated with higher relapse probability at follow-up [206, 213, 215]. Moreover, in AUD patients, alcohol cues elicit activity within limbic and prefrontal structures involved in incentive salience attribution and reward processing, including $\mathrm{mPFC}, \mathrm{OFC}, \mathrm{ACC}$, posterior cingulate cortex, and striatum [212, 216-222]. Interestingly, AUD duration has been shown to correlate with activation of the posterior putamen [212], an area related to habitual control [11]. Moreover, increased frontal activation has been related to decreased dopamine receptor availability in the VS [217], and these cue-elicited fronto-striatal responses have been shown to predict subsequent craving and relapse [218-220]. Specifically, alcohol-cue reactivity in the VS has been suggested as a prognostic factor for relapse in AUD patients [219].

Dovetailing with results in clinical samples, cue reactivity studies with social drinkers have also reported increases in attentional bias [223, 224], heart rate variability [225], and craving [226-228] in response to alcohol cues in heavy drinkers. Interestingly, Roy-Charland et al. [223] observed that participants who consumed more alcohol performed more frequent saccades into and out of alcohol-related image parts, a behavior reminiscent of sign-tracking. Neuroimaging studies have further highlighted the relevance of fronto-striatal circuits, showing how heavy and light alcohol use modulate PFC, ACC, and ventral and dorsal striatal responses to alcohol-related cues [229-231]. While cue reactivity paradigms make use of "naturally", idiosyncratically conditioned cues, a handful of studies have investigated de novo alcohol conditioning in social drinkers so far [232•, 233-236]. Specifically, neutral cues experimentally paired with low to moderate doses of alcohol have been associated with increased skin conductance $[233,236]$ and greater attentional capture $[234,236]$ compared with a CS-, with attentional bias being positively related to participants' self-reported liking of alcohol [234]. In a neuroimaging study, visual background stimuli associated with intravenous alcohol (CS+) compared with saline infusion (CS-) were found to evoke BOLD responses in frontoparietal and orbitofrontal regions, ACC, and insula [235]. However, CS+-elicited BOLD responses were unrelated to recent drinking or other risk factors of AUD, such as a family history of the disorder, and no behavioral conditioning effect could be observed in a reaction time task [235]. A single study has researched alcohol-induced place conditioning in humans [232•]. In a multi-session setup, heavy social drinkers received either alcoholic or nonalcoholic drinks in two distinct rooms, respectively. At test, participants preferred the room previously associated with alcohol consumption compared with the non-alcohol-associated room, i.e., displayed a behavior consistent with conditioned place preference. This effect, however, was independent of explicit awareness of context contingency, suggesting that alcohol cues influence behavior irrespective of drug awareness [232•]. Of note, alcohol conditioning had no effect on subsequent free choice behavior [234, 236], raising questions about when and how the presence of alcohol-associated cues becomes behaviorally relevant.

In summary, this line of research provides evidence that both AUD patients and social drinkers attribute incentive salience to alcohol cues and that conditioned incentive properties may develop largely outside of the participant's awareness. While alcohol-paired cues consistently increased neural and psychophysiological responses in individuals diagnosed with AUD, only few studies have addressed the process of de novo alcohol conditioning in humans.

\section{Influence of Pavlovian Cues on Instrumental Responding: Pavlovian-to-Instrumental Transfer}

\section{Behavioral Paradigms and Neural Circuitry}

Drug-related cues do not only have high impact on psychological and neurophysiological reactions but can also directly influence the motivation to perform certain behaviors. The Pavlovian-to-instrumental transfer (PIT) test has been used to assess the impact of Pavlovian cues on instrumental behavior. Here, positively valued Pavlovian cues enhance instrumental approach behavior [for a review, see 237], while negatively valued Pavlovian cues attenuate instrumental approach behavior [e.g., 238]. Numerous animal studies have assessed PIT [239], typically using a three-stage experimental design [237]: in a first Pavlovian conditioning stage, the animal is presented with a neutral stimulus that is paired with a positive reinforcer, becoming an appetitive $\mathrm{CS}+$; in a second 
instrumental training stage, the animal learns via trial and error to press a lever to receive a desired outcome; and in a final transfer stage, the animal is confronted with the lever (in extinction) and either the CS+ or no cue. The typical PIT effect observed during the transfer stage is an increase in lever presses in trials with the CS+ compared with trials with no cue. So-called full PIT paradigms use several US types to distinguish between general and outcome-specific PIT effects. In general PIT, Pavlovian cues impact instrumental performance irrespective of the associated reward, e.g., ethanolpaired Pavlovian cues can have a general excitatory effect on reward-seeking behavior in rats, affecting both ethanolassociated and sucrose-associated lever pressing [240]. In contrast, in outcome-specific PIT, the impact of Pavlovian cues on instrumental performance is directly linked to the associated reward, e.g., sucrose-associated Pavlovian cues selectively elevate sucrose-directed but not ethanol-directed lever pressing [240]. Several theories have attempted to explain the transfer effect [for a review, see 237]. Initial theories posited that the CS+ elicits a general increase in motivational arousal and activates the memory of the sensory-specific features of the outcome [241-243]. More recent theories include the associative-cybernetic model, which posits an S-O, O-R chain through associative and S-R memories as well as a general enhancement of instrumental actions [244], and hierarchical models, which postulate that the CS enhances instrumental responding because of its predictive value through hierarchical CS-(R-O) associations [245-247].

The PIT paradigm has also been used in humans, with evidence for both general and outcome-specific PIT effects [237, 248-250]. Huys et al. [251] showed distinct effects of appetitive Pavlovian stimuli enhancing approach and inhibiting withdrawal behavior, while aversive stimuli showed the opposite result. These effects were independent of reinforcer presentation delay, which was interpreted as a disruption in goal-directed instrumental control by Pavlovian cues [252]. PIT effects in humans have been shown to be insensitive to outcome-devaluation [253] (although see satiety effects in PIT-related NAcc activation in animals [254]), but sensitive to extinction, although this was less effective for reducing PIT in a different context [255]. Moreover, reduced working memory capacity has been reported to attenuate outcome-specific but not general PIT [256].

On a neural level, animal studies have shown that dopaminergic neurotransmission in subcortical areas, specifically within the NAcc, is crucial for general PIT [257-259]. However, satiety attenuated PIT-related NAcc dopaminergic responses [254], emphasizing the role of this region on cuemotivated behavior [for a review, see 260]. Recent work has also highlighted the role of striatal cholinergic transmission [261-264] and NMDA receptor-mediated signaling [146] for cue-triggered instrumental behavior. Both NAcc and amygdala appear to be essential structures underlying the
PIT effect, with double dissociations reported for both regions. Whereas the NAcc core [265] and the central nucleus of the amygdala $[242,266,267]$ mediate general PIT, the NAcc shell $[265,268]$ and basolateral amygdala $[242,269]$ mediate outcome-specific transfer. Moreover, research suggests that the basolateral amygdala encodes S-O associations and relays this information to the NAcc to mediate goaldirected behavior [270]. The ventral tegmental area [241, 271], DLS [272], infralimbic [273] and medial PFC [274], and OFC $[274,275]$ have been related to both general and/ or outcome-specific PIT effects. Indeed, outcome-specific PIT is thought to rely on the interactions between medial ventral pallidum, NAcc shell, mediodorsal thalamus, and VTA [271, 276], and inactivation of projections from basolateral amygdala to OFC impairs outcome-specific PIT, suggesting they enable cue-triggered reward expectations that drive goaldirected behavior [277].

Neuroimaging studies in humans have reported the involvement of similar structures as rodent research. PITrelated activation has been found within NAcc, putamen, insula, and amygdala [238, 248, 278-281]. Moreover, dopamine depletion [282] and dopamine antagonists [283] have been shown to reduce the influence of appetitive Pavlovian cues on instrumental responses.

\section{Findings in Alcohol Use Disorder and At-Risk Populations}

Preclinical research has demonstrated that alcohol-predictive cues produce a general PIT effect, increasing performance to obtain both alcoholic and non-alcoholic outcomes [240, 284-286]. However, others have reported alcohol-specific PIT effects when both the alcoholic and non-alcoholic outcomes are concurrently available during the transfer test [287, 288]. The influence of Pavlovian cues on instrumental responding has been shown to increase with longer instrumental training [284], but can be abolished if Pavlovian extinction is received prior to the transfer test [287]. As with primary reinforcers, rodent research has shown that the reconsolidation of CS-alcohol memories underlying PIT is mediated by NMDA-receptor neurotransmission [289], and differentiated roles for NAcc shell and core, with core inactivation reducing the general PIT effect induced by alcohol and shell inactivation selectively reducing outcome-specific PIT [285].

Only a few studies have investigated PIT in AUD patients (Table 1). Garbusow et al. [290, 291] investigated general PIT with both monetary (non-drug) and alcohol-related cues, observing enhanced non-drug PIT effects in AUD patients. Specifically, patients failed to inhibit approach behavior when simultaneously confronted with positively valued CS, an effect that was even more pronounced in impulsive AUD patients compared with non-impulsive patients and impulsive healthy controls [292]. This effect further predicted relapse at 1-year follow-up [293]. Non-drug PIT effects were 
associated with NAcc activity, predicting relapse at 3-month follow-up [291]. Similarly, high- compared with low-risk social drinkers also showed stronger non-drug PIT effects, associated with amygdala activation and a cumulative genetic risk for alcohol-related problems [294•].

Conversely, AUD patients compared with healthy controls had a lower general PIT effect elicited by alcohol versus water cues [292, 295], suggesting an inhibition of instrumental performance during alcohol-associated trials. Interestingly, this effect was associated with NAcc activity, and both behavioral and neural effects were driven by patients classified as abstainers at follow-up, who displayed increased NAcc activity at 6-week follow-up and stronger behavioral inhibition at 6month follow-up compared with both healthy controls and individuals that relapsed to alcohol [295]. This rather surprising result dovetails with a study reporting enhanced NAcc and mPFC activation elicited by alcohol versus neutral cues in patients who relapsed at 3-month follow-up [220]. These results are further substantiated by a multivoxel classification scheme showing that alcohol PIT-related mPFC activity predicted relapse in AUD patients and alcohol intake in social drinkers at 1-year follow-up [296•]. In contrast, studies using neutral primary reinforcers (water, chips, snacks) in PIT tasks have found no differences between AUD patients and healthy controls [75, 297]. Research in subclinical populations, including social drinkers, has found no association between alcohol-specific PIT effects and drinking measures (e.g., AUDIT scores) [298-300].

Taken together, these results suggest that strong general PIT effects on approach behavior may increase the risk for alcohol intake in at-risk and AUD participants. However, PIT tasks that use alcohol cues have revealed group differences among AUD patients, with individuals that are able to abstain displaying an inhibitory effect of alcohol cues on approach behavior, whereas individuals that subsequently relapse do not differ from healthy controls. This is in line with the hypothesis that PIT effects may be modulated by goaldirected control [297].

\section{Discussion and Outlook}

Basic learning mechanisms, including Pavlovian and instrumental processes, are crucial to understand the development and maintenance of AUD. Preclinical research has extensively demonstrated that alcohol and alcohol-paired cues heavily influence behavior and induce long-lasting changes in brain circuitry. Animal models evidence that alcohol seeking starts as goal-directed behavior, driven by the DMS [21, 72], but through overtraining becomes consistent with an S-R habit, with behavior that will persist despite negative consequences and is driven by the DLS $[21,60-62,73]$. Moreover, ethanol infusions cause animals to develop conditioned place preference [183-185] and pairing neutral cues with alcohol outcomes induces sign-tracking, whereby animals interact preferentially with the Pavlovian cues [174-178], a behavior that also increases operant responding for alcohol [174, 179]. Indeed, alcohol-predicting Pavlovian cues have been shown to elicit a general PIT effect, increasing responses to obtain both alcoholic and non-alcoholic outcomes [240, 284-286]. As with instrumental conditioning, these Pavlovian processes depend heavily on striato-limbic circuitry, especially NAcc and amygdala [185, 193, 197, 285], as well as NMDA receptor and dopaminergic signaling [178, 182, 185, 194, 289].

Translation of animal research to humans remains, however, challenging, with less clear-cut findings than animal studies due, at least in part, to heterogeneity in the paradigms used, employed measures of conditioning (implicit physiological, explicit self-report or neuronal), level of awareness about the conditioning procedure and modifying factors, such as comorbidities, AUD severity and duration, or context (e.g., enrollment in treatment programs or recent detoxification). This notwithstanding, alcohol cues have been extensively proven to induce attentional and psychophysiological changes and increase craving in individuals with AUD [202-204, 206-215], as well as social drinkers [223-228]. However, in contrast to animal research, conditioning of alcohol cues in human studies has usually taken place outside of the experimenter's control and is thus subject to an indeterminate number of potential confounders. Still, recent attempts at de novo Pavlovian conditioning with alcohol, a procedure more similar to preclinical methods, have proven successful, underlining the role of a number of limbic and prefrontal structures [235] and demonstrating alcohol-induced conditioned place preference in social drinkers [232•].

In the instrumental domain, individuals with AUD exhibit decreased goal-directed/model-based control [74•, 77], as well as decreased $\mathrm{mPFC}$ and increased dorsal striatal activity in AUD participants [74•, 78••], consistent with rodent studies showing that ethanol exposure results in fronto-striatal changes that contribute to the loss of goal-directed control [67]. However, not all studies have observed differences in model-based versus model-free control [78••, 79]. Translation of research in animals to humans remains a major challenge also in instrumental learning studies. The overtraining-induced shift from goal-directed to habitual control found in rodents $[11,113,301]$ has proven elusive in humans [302] (although see Hardwick et al. [303] for a novel design to test habitual responding in humans after overtraining). Moreover, some authors [26, 304] have questioned the suitability of the formalization of habit and goal-directed processes as model-free and model-based control $[27,32]$ for the study of habit behavior in humans at all. In light of these issues, alternative computational architectures have been proposed [for a review of other taxonomies, see 16] that might better align with classical behavioral findings 
across species. Furthermore, the recent back-translation of the two-step task for rodents [33-37] could also shed light on these issues. Indeed, translation of models and methodologies between preclinical and clinical research is crucial in the study of basic learning mechanisms in AUD. In recent years, the few human PIT studies exploring AUD have started to elucidate the influence of Pavlovian cues on instrumental behavior, revealing stronger PIT effects in AUD patients [290-292, 295]. Recent lines of research that have started incorporating animal concepts, e.g., sign- versus goal-trackers, into human studies $[121,122 \bullet \bullet]$ will certainly promote understanding of the relationship between Pavlovian and instrumental behavior.

The studies detailed above have further started to unearth the complex relationship between these basic learning processes and abstinence and relapse. Indeed, cue reactivity as reflected by psychophysiological changes and VS activation has been related to the probability of relapse at follow-up [206, 213, 215, 219, 220]. Similarly, model-based control, together with alcohol expectancies, could be both a predictor of long-term abstinence [78••] and improve with long-term abstinence [79]. PIT-associated fronto-striatal changes have also been related to relapse risk [291, 295, 296•]. Animal models seem here particularly relevant, as they could help tease out the potential components influencing the long-term maintenance of abstinence and have already demonstrated how treatments influencing fronto-striatal function can improve goal-directed control [21, 67, 73]. Preclinical models are also irreplaceable in order to study the influence of age and gender in AUD development, a field that human research can only explore retrospectively, but in which rodent studies have already provided powerful insights [69-71, 180-182].

A better understanding of the outlined instrumental and Pavlovian learning processes involved in the development, maintenance, and relapse of AUD ultimately holds promise to improve individualized treatment options for this disorder. Novel intervention strategies that target automated approach tendencies and potentially also craving elicited by Pavlovian conditioned cues include cognitive bias modification [305-307], pharmacological adjuncts to boost cue exposure therapy [308, 309], or techniques focusing on reconsolidation processes [310-312] (reviewed in detail by Beck et al. in this issue).

In order to reach this goal, research should aim for longitudinal studies using reliable and ecologically valid paradigms of Pavlovian and instrumental processes with alcohol-related cues and outcomes, which should be combined with state-ofthe-art imaging techniques, computational modeling, and ecological momentary assessment methods that collect real-time craving and substance use data in daily life [313]. This will allow us to better understand how these basic learning mechanisms contribute to the initial development and maintenance of AUD.
Acknowledgments We thank Anna Berglöf, Katharina Cygan, Lukas Dada, and Lilly Nagel for their assistance with the literature search.

Funding Open Access funding enabled and organized by Projekt DEAL. This work was supported by the Deutsche Forschungsgemeinschaft (DFG, German Research Foundation) with grants DO1915/3-1 to N.D, SCHL1969/5-1 to F.S., HE2597/14-1, HE2597/14-2 to A.H., and SFB/ TRR 265 (Project-ID 402170461 [313], projects B1 to F.S. and B3 to A.H.) , and the Bundesministerium für Bildung und Forschung (BMBF, Federal Ministry of Education and Research) with grants 01GQ0411, 01QG87164, NGFN Plus 01GS08152, and 01GS08159. Funders had no role in the writing of the report or in the decision to submit the paper for publication.

Bundesministerium für Bildung und Forschung (DE) and Deutsche Forschungsgemeinschaft (DE).

\section{Compliance with Ethical Standards}

Conflict of Interest The authors report no biomedical financial interests or conflict of interest.

Human and Animal Rights and Informed Consent This article does not report primary data. The regulatory statements of the articles reviewed apply.

Open Access This article is licensed under a Creative Commons Attribution 4.0 International License, which permits use, sharing, adaptation, distribution and reproduction in any medium or format, as long as you give appropriate credit to the original author(s) and the source, provide a link to the Creative Commons licence, and indicate if changes were made. The images or other third party material in this article are included in the article's Creative Commons licence, unless indicated otherwise in a credit line to the material. If material is not included in the article's Creative Commons licence and your intended use is not permitted by statutory regulation or exceeds the permitted use, you will need to obtain permission directly from the copyright holder. To view a copy of this licence, visit http://creativecommons.org/licenses/by/4.0/.

\section{References}

Papers of particular interest, published recently, have been highlighted as:

- Of importance

•- Of major importance

1. Everitt BJ, Robbins TW. Neural systems of reinforcement for drug addiction: from actions to habits to compulsion. Nat Neurosci. 2005;8(11):1481-9. https://doi.org/10.1038/nn1579.

2. Everitt BJ, Belin D, Economidou D, Pelloux Y, Dalley JW, Robbins TW. Neural mechanisms underlying the vulnerability to develop compulsive drug-seeking habits and addiction. Philos Trans R Soc B. 2008;363(1507):3125-35. https://doi.org/10. 1098/rstb.2008.0089.

3. Everitt BJ, Robbins TW. Drug addiction: updating actions to habits to compulsions ten years on. Annu Rev Psychol. 2016;67(1):23-50. https://doi.org/10.1146/annurev-psych122,414-033457.

4. Jentsch JD, Taylor JR. Impulsivity resulting from frontostriatal dysfunction in drug abuse: implications for the control of behavior 
by reward-related stimuli. Psychopharmacology. 1999;146(4): 373-90. https://doi.org/10.1007/p100005483.

5. Bossert JM, Marchant NJ, Calu DJ, Shaham Y. The reinstatement model of drug relapse: recent neurobiological findings, emerging research topics, and translational research. Psychopharmacology. 2013;229(3):453-76. https://doi.org/10.1007/s00213-013-3120y.

6. Heinz A. A new understanding of mental disorders: computational models for dimensional psychiatry. Cambridge: MIT Press; 2017.

7. Berridge KC, Robinson TE. Liking, wanting, and the incentivesensitization theory of addiction. Am Psychol. 2016;71(8):670-9. https://doi.org/10.1037/amp0000059.

8. Robinson TE, Berridge KC. The neural basis of drug craving: an incentive-sensitization theory of addiction. Brain Res Rev. 1993;18(3):247-91. https://doi.org/10.1016/0165-0173(93) 90013-p.

9. Koob GF. Negative reinforcement in drug addiction: the darkness within. Curr Opin Neurobiol. 2013;23(4):559-63. https://doi.org/ 10.1016/j.conb.2013.03.011

10. Balleine BW, Dickinson A. Goal-directed instrumental action: contingency and incentive learning and their cortical substrates. Neuropharmacology. 1998;37(4):407-19. https://doi.org/10. 1016/s0028-3908(98)00033-1.

11. Balleine BW, O'Doherty JP. Human and rodent homologies in action control: corticostriatal determinants of goal-directed and habitual action. Neuropsychopharmacology. 2010;35(1):48-69. https://doi.org/10.1038/npp.2009.131.

12. Thorndike EL. Animal intelligence: experimental studies. New York: Macmillan; 1911.

13. Dolan RJ, Dayan P. Goals and habits in the brain. Neuron. 2013;80(2):312-25. https://doi.org/10.1016/j.neuron.2013.09. 007.

14. Dayan P. Goal-directed control and its antipodes. Neural Netw. 2009;22(3):213-9. https://doi.org/10.1016/j.neunet.2009.03.004.

15. Dickinson A, Balleine BW. Causal cognition and goal-directed action. In: Heyes C, Huber L, editors. Vienna series in theoretical biology. The evolution of cognition. Cambridge: The MIT Press; 2000. p. 185-204.

16. Miller KJ, Ludvig EA, Pezzulo G, Shenhav A. Realigning models of habitual and goal-directed decision-making. In: Morris RW, Bornstein AM, Shenhav A, editors. Goal-directed decision making: computations and neural circuits. Cambridge: Academic Press; 2018. p. 407-28.

17. Liljeholm M, Tricomi E, O’Doherty JP, Balleine BW. Neural correlates of instrumental contingency learning: differential effects of action-reward conjunction and disjunction. J Neurosci. 2011;31(7):2474-80. https://doi.org/10.1523/jneurosci.3354-10. 2011.

18. Adams CD, Dickinson A. Instrumental responding following reinforcer devaluation. Q J Exp Psychol B. 1981;33(2b):109-21. https://doi.org/10.1080/14640748108400816.

19. Valentin VV, Dickinson A, O'Doherty JP. Determining the neural substrates of goal-directed learning in the human brain. J Neurosci. 2007;27(15):4019-26. https://doi.org/10.1523/ jneurosci.0564-07.2007.

20. de Wit S, Niry D, Wariyar R, Aitken MRF, Dickinson A. Stimulus-outcome interactions during instrumental discrimination learning by rats and humans. J Exp Psychol Anim Behav Process. 2007;33(1):1-11. https://doi.org/10.1037/0097-7403.33. 1.1 .

21. Corbit LH, Nie H, Janak PH. Habitual alcohol seeking: time course and the contribution of subregions of the dorsal striatum. Biol Psychiatry. 2012;72(5):389-95. https://doi.org/10.1016/j. biopsych.2012.02.024.

22. Chatlosh DL, Neunaber DJ, Wasserman EA. Response-outcome contingency: behavioral and judgmental effects of appetitive and aversive outcomes with college students. Learn Motiv. 1985;16(1):1-34. https://doi.org/10.1016/0023-9690(85)90002-5.

23. Shanks DR, Dickinson A. Instrumental judgment and performance under variations in action-outcome contingency and contiguity. Mem Cogn. 1991;19(4):353-60. https://doi.org/10.3758/ bf03197139.

24. Hammond LJ. The effect of contingency upon the appetitive conditioning of free-operant behavior. J Exp Anal Behav. 1980;34(3): 297-304. https://doi.org/10.1901/jeab.1980.34-297.

25. Dickinson A, Mulatero CW. Reinforcer specificity of the suppression of instrumental performance on a non-contingent schedule. Behav Process. 1989;19(1):167-80. https://doi.org/10.1016/03766357(89)90039-9.

26. Patterson TK, Knowlton BJ. Subregional specificity in human striatal habit learning: a meta-analytic review of the fMRI literature. Curr Opin Behav Sci. 2018;20:75-82. https://doi.org/10. 1016/j.cobeha.2017.10.005.

27. Daw ND, Niv Y, Dayan P. Uncertainty-based competition between prefrontal and dorsolateral striatal systems for behavioral control. Nat Neurosci. 2005;8(12):1704-11. https://doi.org/10. 1038/nn1560.

28. Daw ND, Gershman Samuel J, Seymour B, Dayan P, Dolan RJ. Model-based influences on humans' choices and striatal prediction errors. Neuron. 2011;69(6):1204-15. https://doi.org/10.1016/ j.neuron.2011.02.027.

29. Doll BB, Duncan KD, Simon DA, Shohamy D, Daw ND. Modelbased choices involve prospective neural activity. Nat Neurosci. 2015;18(5):767-72. https://doi.org/10.1038/nn.3981.

30. Deserno L, Wilbertz T, Reiter A, Horstmann A, Neumann J, Villringer A, et al. Lateral prefrontal model-based signatures are reduced in healthy individuals with high trait impulsivity. Transl Psychiatry. 2015;5:E659. https://doi.org/10.1038/tp.2015.139.

31. Nebe S, Kroemer NB, Schad DJ, Bernhardt N, Sebold M, Müller DK, et al. No association of goal-directed and habitual control with alcohol consumption in young adults. Addict Biol. 2018;23(1):379-93. https://doi.org/10.1111/adb.12490.

32. Kool W, Cushman FA, Gershman SJ. When does model-based control pay off? PLoS Comput Biol. 2016;12(8):E1005090. https://doi.org/10.1371/journal.pcbi.1005090.

33. Akam T, Rodrigues-Vaz I, Marcelo I, Zhang X, Pereira M, Oliveira RF et al. Anterior cingulate cortex represents actionstate predictions and causally mediates model-based reinforcement learning in a two-step decision task. bioRxiv. preprint. https://doi.org/10.1101/126292.

34. Hasz BM, Redish AD. Deliberation and procedural automation on a two-step task for rats. Front Integr Neurosci. 2018;12(30). https://doi.org/10.3389/fnint.2018.00030.

35. Groman SM, Massi B, Mathias SR, Lee D, Taylor JR. Model-free and model-based influences in addiction-related behaviors. Biol Psychiatry. 2019;85(11):936-45. https://doi.org/10.1016/j. biopsych.2018.12.017.

36. Dezfouli A, Balleine BW. Learning the structure of the world: the adaptive nature of state-space and action representations in multistage decision-making. PLoS Comput Biol. 2019;15(9): E1007334. https://doi.org/10.1371/journal.pcbi.1007334.

37. Miller KJ, Botvinick MM, Brody CD. Dorsal hippocampus contributes to model-based planning. Nat Neurosci. 2017;20(9): 1269-76. https://doi.org/10.1038/nn.4613.

38. Economides M, Kurth-Nelson Z, Lübbert A, Guitart-Masip M, Dolan RJ. Model-based reasoning in humans becomes automatic with training. PLoS Comput Biol. 2015;11(9):E1004463. https:// doi.org/10.1371/journal.pcbi.1004463.

39. Izquierdo A, Suda RK, Murray EA. Bilateral orbital prefrontal cortex lesions in rhesus monkeys disrupt choices guided by both reward value and reward contingency. J Neurosci. 2004;24(34): 7540-8. https://doi.org/10.1523/jneurosci.1921-04.2004. 
40. Izquierdo A, Murray EA. Combined unilateral lesions of the amygdala and orbital prefrontal cortex impair affective processing in rhesus monkeys. J Neurophysiol. 2004;91(5):2023-39. https:// doi.org/10.1152/jn.00968.2003.

41. Gourley SL, Zimmermann KS, Allen AG, Taylor JR. The medial orbitofrontal cortex regulates sensitivity to outcome value. J Neurosci. 2016;36(16):4600-13. https://doi.org/10.1523/ jneurosci.4253-15.2016.

42. Baxter MG, Parker A, Lindner CCC, Izquierdo AD, Murray EA. Control of response selection by reinforcer value requires interaction of amygdala and orbital prefrontal cortex. J Neurosci. 2000;20(11):4311-9. https://doi.org/10.1523/jneurosci.20-1104311.2000 .

43. Gourley SL, Olevska A, Zimmermann KS, Ressler KJ, DiLeone RJ, Taylor JR. The orbitofrontal cortex regulates outcome-based decision-making via the lateral striatum. Eur J Neurosci. 2013;38(3):2382-8. https://doi.org/10.1111/ejn.12239.

44. Ostlund SB, Balleine BW. Lesions of medial prefrontal cortex disrupt the acquisition but not the expression of goal-directed learning. J Neurosci. 2005;25(34):7763-70. https://doi.org/10. 1523/jneurosci.1921-05.2005.

45. Corbit LH, Balleine BW. The role of prelimbic cortex in instrumental conditioning. Behav Brain Res. 2003;146(1):145-57. https://doi.org/10.1016/j.bbr.2003.09.023.

46. Killcross S, Coutureau E. Coordination of actions and habits in the medial prefrontal cortex of rats. Cereb Cortex. 2003;13(4):400-8. https://doi.org/10.1093/cercor/13.4.400.

47. Naneix F, Marchand AR, Scala GD, Pape J-R, Coutureau E. A role for medial prefrontal dopaminergic innervation in instrumental conditioning. J Neurosci. 2009;29(20):6599-606. https://doi. org/10.1523/jneurosci.1234-09.2009.

48. Yin HH, Ostlund SB, Knowlton BJ, Balleine BW. The role of the dorsomedial striatum in instrumental conditioning. Eur $\mathrm{J}$ Neurosci. 2005;22(2):513-23. https://doi.org/10.1111/j.14609568.2005.04218.x.

49. Yin HH, Knowlton BJ, Balleine BW. Lesions of dorsolateral striatum preserve outcome expectancy but disrupt habit formation in instrumental learning. Eur J Neurosci. 2004;19(1):181-9. https:// doi.org/10.1111/j.1460-9568.2004.03095.x.

50. Liljeholm M, Dunne S, O’Doherty JP. Differentiating neural systems mediating the acquisition vs. expression of goal-directed and habitual behavioral control. Eur J Neurosci. 2015;41(10):135871. https://doi.org/10.1111/ejn.12897.

51. de Wit S, Corlett PR, Aitken MRF, Dickinson A, Fletcher PC. Differential engagement of the ventromedial prefrontal cortex by goal-directed and habitual behavior towards food pictures in humans. J Neurosci. 2009;29(36):11330-8. https://doi.org/10. 1523/jneurosci.1639-09.2009.

52. de Wit S, Watson P, Harsay HA, Cohen MX, van de Vijver I, Ridderinkhof KR. Corticostriatal connectivity underlies individual differences in the balance between habitual and goal-directed action control. J Neurosci. 2012;32(35):12066-75. https://doi.org/ 10.1523/jneurosci.1088-12.2012.

53. Tanaka SC, Balleine BW, O'Doherty JP. Calculating consequences: brain systems that encode the causal effects of actions. J Neurosci. 2008;28(26):6750-5. https://doi.org/10.1523/ jneurosci.1808-08.2008.

54. Reber J, Feinstein JS, O’Doherty JP, Liljeholm M, Adolphs R, Tranel D. Selective impairment of goal-directed decision-making following lesions to the human ventromedial prefrontal cortex. Brain. 2017;140(6):1743-56. https://doi.org/10.1093/brain/ awx105.

55. O'Callaghan C, Vaghi MM, Brummerloh B, Cardinal RN, Robbins TW. Impaired awareness of action-outcome contingency and causality during healthy aging and following ventromedial prefrontal cortex lesions. Neuropsychologia. 2019;128:282-9. https://doi.org/10.1016/j.neuropsychologia.2018.01.021.

56. Gläscher J, Daw ND, Dayan P, O'Doherty JP. States versus rewards: dissociable neural prediction error signals underlying model-based and model-free reinforcement learning. Neuron. 2010;66(4):585-95. https://doi.org/10.1016/j.neuron.2010.04. 016.

57. Morris RW, Dezfouli A, Griffiths KR, Balleine BW. Action-value comparisons in the dorsolateral prefrontal cortex control choice between goal-directed actions. Nat Commun. 2014;5:4390. https://doi.org/10.1038/ncomms5390.

58. Smittenaar P, FitzGerald Thomas HB, Romei V, Wright Nicholas D, Dolan RJ. Disruption of dorsolateral prefrontal cortex decreases model-based in favor of model-free control in humans. Neuron. 2013;80(4):914-9. https://doi.org/10.1016/j.neuron. 2013.08.009.

59. Vikbladh OM, Meager MR, King J, Blackmon K, Devinsky O, Shohamy D, et al. Hippocampal contributions to model-based planning and spatial memory. Neuron. 2019;102(3):683-93.e4. https://doi.org/10.1016/j.neuron.2019.02.014.

60. Dickinson A, Wood N, Smith JW. Alcohol seeking by rats: action or habit? Q J Exp Psychol B. 2002;55(4b):331-48. https://doi.org/ 10.1080/0272499024400016.

61. Lesscher HMB, Van Kerkhof LWM, Vanderschuren LJMJ. Inflexible and indifferent alcohol drinking in male mice. Alcohol Clin Exp Res. 2010;34(7):1219-25. https://doi.org/10.1111/j. 1530-0277.2010.01199.x.

62. Hopf FW, Chang S-J, Sparta DR, Bowers MS, Bonci A. Motivation for alcohol becomes resistant to quinine adulteration after 3 to 4 months of intermittent alcohol self-administration. Alcohol Clin Exp Res. 2010;34(9):1565-73. https://doi.org/10. 1111/j.1530-0277.2010.01241.x.

63. Renteria R, Cazares C, Gremel CM. Habitual ethanol seeking and licking microstructure of enhanced ethanol self-administration in ethanol-dependent mice. Alcohol Clin Exp Res. 2020;44(4):880 91. https://doi.org/10.1111/acer.14302.

64. López MF, Becker HC, Chandler LJ. Repeated episodes of chronic intermittent ethanol promote insensitivity to devaluation of the reinforcing effect of ethanol. Alcohol. 2014;48(7):639-45. https:// doi.org/10.1016/j.alcohol.2014.09.002.

65. Barker JM, Bryant KG, Montiel-Ramos A, Goldwasser B, Chandler LJ. Selective deficits in contingency-driven ethanol seeking following chronic ethanol exposure in male mice. Alcohol Clin Exp Res. in press. https://doi.org/10.1111/acer. 14418.

66. Houck CA, Grahame NJ. Acute drug effects on habitual and nonhabitual responding in crossed high alcohol preferring mice. Psychopharmacology. 2018;235(7):2167-75. https://doi.org/10. 1007/s00213-018-4914-8.

67. Renteria R, Baltz ET, Gremel CM. Chronic alcohol exposure disrupts top-down control over basal ganglia action selection to produce habits. Nat Commun. 2018;9(1):211. https://doi.org/10. 1038/s41467-017-02615-9.

68. Ostlund SB, Maidment NT, Balleine BW. Alcohol-paired contextual cues produce an immediate and selective loss of goal-directed action in rats. Front Integr Neurosci. 2010;4(19). https://doi.org/ 10.3389/fnint.2010.00019.

69. Barker JM, Torregrossa MM, Arnold AP, Taylor JR. Dissociation of genetic and hormonal influences on sex differences in alcoholism-related behaviors. J Neurosci. 2010;30(27):9140-4. https://doi.org/10.1523/jneurosci.0548-10.2010.

70. Serlin H, Torregrossa MM. Adolescent rats are resistant to forming ethanol seeking habits. Dev Cogn Neurosci. 2015;16: 183-90. https://doi.org/10.1016/j.den.2014.12.002.

71. Barker JM, Bryant KG, Osborne JI, Chandler LJ. Age and sex interact to mediate the effects of intermittent, high-dose ethanol 
exposure on behavioral flexibility. Front Pharmacol. 2017;8(450). https://doi.org/10.3389/fphar.2017.00450.

72. Fanelli RR, Klein JT, Reese RM, Robinson DL. Dorsomedial and dorsolateral striatum exhibit distinct phasic neuronal activity during alcohol self-administration in rats. Eur J Neurosci. 2013;38(4): 2637-48. https://doi.org/10.1111/ejn.12271.

73. Corbit LH, Nie H, Janak PH. Habitual responding for alcohol depends upon both AMPA and $\mathrm{D}_{2}$ receptor signaling in the dorsolateral striatum. Front Behav Neurosci. 2014;8:301. https://doi. org/10.3389/fnbeh.2014.00301.

74. Sjoerds Z, de Wit S, van den Brink W, Robbins TW, Beekman ATF, Penninx BWJH, et al. Behavioral and neuroimaging evidence for overreliance on habit learning in alcohol-dependent patients. Transl Psychiatry. 2013;3:E337. https://doi.org/10.1038/tp. 2013.107 This article was the first to describe impairments in goal-directed behavior and related fronto-striatal changes in individuals with AUD.

75. van Timmeren T, Quail SL, Balleine BW, Geurts DEM, Goudriaan AE, van Holst RJ. Intact corticostriatal control of goal-directed action in alcohol use disorder: a Pavlovian-toinstrumental transfer and outcome-devaluation study. Sci Rep. 2020;10(1):4949. https://doi.org/10.1038/s41598-020-61,892-5.

76. Morris RW, Quail S, Griffiths KR, Green MJ, Balleine BW. Corticostriatal control of goal-directed action is impaired in schizophrenia. Biol Psychiatry. 2015;77(2):187-95. https://doi. org/10.1016/j.biopsych.2014.06.005.

77. Sebold M, Deserno L, Nebe S, Schad DJ, Garbusow M, Hägele C, et al. Model-based and model-free decisions in alcohol dependence. Neuropsychobiology. 2014;70(2):122-31. https://doi.org/ $10.1159 / 000362840$

78.• Sebold M, Nebe S, Garbusow M, Guggenmos M, Schad D, Beck A, et al. When habits are dangerous - alcohol expectancies and habitual decision-making predict relapse in alcohol dependence. Biol Psychiatry. 2017;82(11):847-56. https://doi.org/10.1016/j. biopsych.2017.04.019 This study related impairments in model-based behavior in AUD participants with long-term relapse risk, suggesting that goal-directed control could be a treatment outcome predictor.

79. Voon V, Derbyshire K, Rück C, Irvine MA, Worbe Y, Enander J, et al. Disorders of compulsivity: a common bias towards learning habits. Mol Psychiatry. 2015;20:345-52. https://doi.org/10.1038/ mp.2014.44.

80. Doñamayor N, Strelchuk D, Baek K, Banca P, Voon V. The involuntary nature of binge drinking: goal directedness and awareness of intention. Addict Biol. 2018;23(1):515-26. https://doi.org/ 10.1111/adb.12505.

81. Babor TF, Higgins-Biddle JC, Saunders JB, Monteiro MG, World Health Organization. Dept. of Mental Health and Substance Dependence. AUDIT: The Alcohol Use Disorders Identification Test. Guidelines for use in primary health care. 2nd ed. Geneva, Switzerland: World Health Organization; 2001.

82. Saunders JB, Aasland OG, Babor TF, De La Fuente JR, Grant M. Development of the Alcohol Use Disorders Identification Test (AUDIT): WHO collaborative project on early detection of persons with harmful alcohol consumption-II. Addiction. 1993;88(6): 791-804. https://doi.org/10.1111/j.1360-0443.1993.tb02093.x.

83. Gillan CM, Kosinski M, Whelan R, Phelps EA, Daw ND. Characterizing a psychiatric symptom dimension related to deficits in goal-directed control. Elife. 2016;5:E11305. https://doi.org/ 10.7554/elife.11305.

84. Otto AR, Raio CM, Chiang A, Phelps EA, Daw ND. Workingmemory capacity protects model-based learning from stress. Proc Natl Acad Sci U S A. 2013;110(52):20941-6. https://doi.org/10. 1073/pnas.1312011110.

85. Kool W, Gershman SJ, Cushman FA. Cost-benefit arbitration between multiple reinforcement-learning systems. Psychol Sci.
2017;28(9):1321-33. https://doi.org/10.1177/ 0956797617708288 .

86. Patzelt EH, Kool W, Millner AJ, Gershman SJ. Incentives boost model-based control across a range of severity on several psychiatric constructs. Biol Psychiatry. 2019;85(5):425-33. https://doi. org/10.1016/j.biopsych.2018.06.018.

87. Pavlov IP. Conditioned reflexes. Oxford: Oxford University Press; 1927.

88. Bouton ME. Context and behavioral processes in extinction. Learn Mem. 2004;11(5):485-94. https://doi.org/10.1101/lm. 78804.

89. Bouton ME. Context, ambiguity, and unlearning: sources of relapse after behavioral extinction. Biol Psychiatry. 2002;52(10): 976-86. https://doi.org/10.1016/s0006-3223(02)01546-9.

90. Saunders BT, Robinson TE. Individual variation in resisting temptation: implications for addiction. Neurosci Biobehav Rev. 2013;37(9, Part A):1955-75. https://doi.org/10.1016/j.neubiorev. 2013.02.008.

91. Tomie A, di Poce J, Derenzo CC, Pohorecky LA. Autoshaping of ethanol drinking: an animal model of binge drinking. Alcohol Alcohol. 2002;37(2):138-46. https://doi.org/10.1093/alcalc/37.2. 138.

92. Tomie A, Grimes KL, Pohorecky LA. Behavioral characteristics and neurobiological substrates shared by Pavlovian sign-tracking and drug abuse. Brain Res Rev. 2008;58(1):121-35. https://doi. org/10.1016/j.brainresrev.2007.12.003.

93. Martin-Fardon R, Weiss F. Modeling relapse in animals. In: Sommer WH, Spanagel R, editors. Behavioral neurobiology of alcohol addiction. Current topics in behavioral neurosciences. Berlin Heidelberg: Springer; 2013. p. 403-32. https://doi.org/10. 1007/978-3-642-28720-6 202

94. Myers KM, Carlezon WA. Extinction of drug- and withdrawalpaired cues in animal models: relevance to the treatment of addiction. Neurosci Biobehav Rev. 2010;35(2):285-302. https://doi. org/10.1016/j.neubiorev.2010.01.011.

95. Tzschentke TM. Measuring reward with the conditioned place preference (CPP) paradigm: update of the last decade. Addict Biol. 2007;12(3-4):227-462. https://doi.org/10.1111/j.13691600.2007.00070.x.

96. Di Sebastiano AR, Wilson-Pérez HE, Lehman MN, Coolen LM. Lesions of orexin neurons block conditioned place preference for sexual behavior in male rats. Horm Behav. 2011;59(1):1-8. https://doi.org/10.1016/j.yhbeh.2010.09.006.

97. Del Rio D, Cano V, Martín-Ramos M, Gómez M, Morales L, Del Olmo N, et al. Involvement of the dorsomedial prefrontal cortex in high-fat food conditioning in adolescent mice. Behav Brain Res. 2015;283:227-32. https://doi.org/10.1016/j.bbr.2015.01.039.

98. Rubinow MJ, Hagerbaumer DA, Juraska JM. The foodconditioned place preference task in adolescent, adult and aged rats of both sexes. Behav Brain Res. 2009;198(1):263-6. https:// doi.org/10.1016/j.bbr.2008.11.024.

99. Amancio-Belmont O, Romano-López A, Ruiz-Contreras AE, Méndez-Díaz M, Prospéro-García O. From adolescent to elder rats: motivation for palatable food and cannabinoids receptors. Dev Neurobiol. 2017;77(8):917-27. https://doi.org/10.1002/ dneu.22472.

100. Perks SM, Clifton PG. Reinforcer revaluation and conditioned place preference. Physiol Behav. 1997;61(1):1-5. https://doi.org/ 10.1016/s0031-9384(96)00243-0.

101. Aguilar MA, Rodríguez-Arias M, Miñarro J. Neurobiological mechanisms of the reinstatement of drug-conditioned place preference. Brain Res Rev. 2009;59(2):253-77. https://doi.org/10. 1016/j.brainresrev.2008.08.002.

102. Yin HH, Knowlton BJ. Reinforcer devaluation abolishes conditioned cue preference: evidence for stimulus-stimulus 
associations. Behav Neurosci. 2002;116(1):174-7. https://doi.org/ 10.1037/0735-7044.116.1.174.

103. Meyer PJ, Lovic V, Saunders BT, Yager LM, Flagel SB, Morrow $\mathrm{JD}$, et al. Quantifying individual variation in the propensity to attribute incentive salience to reward cues. PLoS ONE. 2012;7(6):e38987. https://doi.org/10.1371/journal.pone.0038987.

104. Flagel SB, Watson SJ, Robinson TE, Akil H. Individual differences in the propensity to approach signals vs goals promote different adaptations in the dopamine system of rats. Psychopharmacology. 2007;191(3):599-607. https://doi.org/10. 1007/s00213-006-0535-8.

105. Boakes RA, Westbrook RF, Elliott M, Swinbourne AL. Context dependency of conditioned aversions to water and sweet tastes. J Exp Psychol Anim Behav Process. 1997;23(1):56-67. https://doi. org/10.1037//0097-7403.23.1.56.

106. Flagel SB, Watson SJ, Akil H, Robinson TE. Individual differences in the attribution of incentive salience to a reward-related cue: influence on cocaine sensitization. Behav Brain Res. 2008;186(1):48-56. https://doi.org/10.1016/j.bbr.2007.07.022.

107. Robinson TE, Flagel SB. Dissociating the predictive and incentive motivational properties of reward-related cues through the study of individual differences. Biol Psychiatry. 2009;65(10):869-73. https://doi.org/10.1016/j.biopsych.2008.09.006.

108. Flagel SB, Akil H, Robinson TE. Individual differences in the attribution of incentive salience to reward-related cues: implications for addiction. Neuropharmacology. 2009;56:139-48. https:// doi.org/10.1016/j.neuropharm.2008.06.027.

109. Flagel SB, Robinson TE. Neurobiological basis of individual variation in stimulus-reward learning. Curr Opin Behav Sci. 2017;13: 178-85. https://doi.org/10.1016/j.cobeha.2016.12.004.

110. Keefer SE, Bacharach SZ, Kochli DE, Chabot JM, Calu DJ. Effects of limited and extended Pavlovian training on devaluation sensitivity of sign- and goal-tracking rats. Front Behav Neurosci. 2020;14(3). https://doi.org/10.3389/fnbeh.2020.00003.

111. Nasser HM, Chen Y-W, Fiscella K, Calu DJ. Individual variability in behavioral flexibility predicts sign-tracking tendency. Front Behav Neurosci. 2015;9(289). https://doi.org/10.3389/fnbeh. 2015.00289.

112. Morrison SE, Bamkole MA, Nicola SM. Sign tracking, but not goal tracking, is resistant to outcome devaluation. Front Neurosci. 2015;9(468). https://doi.org/10.3389/fnins.2015.00468.

113. Adams CD. Variations in the sensitivity of instrumental responding to reinforcer devaluation. Q J Exp Psychol B. 1982;34(2):77-98. https://doi.org/10.1080/14640748208400878.

114. Derman RC, Schneider K, Juarez S, Delamater AR. Sign-tracking is an expectancy-mediated behavior that relies on prediction error mechanisms. Learn Mem. 2018;25(10):550-63. https://doi.org/ 10.1101/lm.047365.118.

115. Cleland GG, Davey GCL. The effects of satiation and reinforcer devaluation on signal-centered behavior in the rat. Learn Motiv. 1982;13(3):343-60. https://doi.org/10.1016/0023-9690(82) 90014-5.

116. Andreatta M, Pauli P. Appetitive vs. aversive conditioning in humans. Front Behav Neurosci. 2015;9:128. https://doi.org/10. 3389/fnbeh.2015.00128.

117. Ebrahimi C, Koch SP, Pietrock C, Fydrich T, Heinz A, Schlagenhauf F. Opposing roles for amygdala and vmPFC in the return of appetitive conditioned responses in humans. Transl Psychiatry. 2019;9:148. https://doi.org/10.1038/s41398-0190482-x.

118. Pietrock C, Ebrahimi C, Katthagen TM, Koch SP, Heinz A, Rothkirch M, et al. Pupil dilation as an implicit measure of appetitive Pavlovian learning. Psychophysiology. 2019;56(12): E13463. https://doi.org/10.1111/psyp.13463.

119. Lonsdorf TB, Menz MM, Andreatta M, Fullana MA, Golkar A, Haaker J, et al. Do not fear 'fear conditioning': methodological considerations for the design and analysis of studies on human fear acquisition, extinction, and return of fear. Neurosci Biobehav Rev. 2017;77:247-85. https://doi.org/10.1016/j.neubiorev.2017.02. 026.

120. Kruse O, Klein S, Tapia León I, Stark R, Klucken T. Amygdala and nucleus accumbens involvement in appetitive extinction. Hum Brain Mapp. 2020;41(7):1833-41. https://doi.org/10.1002/ hbm. 24915.

121. Garofalo S, di Pellegrino G. Individual differences in the influence of task-irrelevant Pavlovian cues on human behavior. Front Behav Neurosci. 2015;9(163). https://doi.org/10.3389/fnbeh.2015. 00163.

122.• Schad DJ, Rapp MA, Garbusow M, Nebe S, Sebold M, Obst E, et al. Dissociating neural learning signals in human sign- and goaltrackers. Nat Hum Behav. 2020;4(2):201-14. https://doi.org/10. 1038/s41562-019-0765-5 The authors translated the distinction between sign- and goal-trackers to healthy human participants, with sign- compared to goal-trackers showing striatal model-free prediction error responses as well as a stronger influence of Pavlovian cues on instrumental behavior.

123. Joyner MA, Gearhardt AN, Flagel SB. A translational model to assess sign-tracking and goal-tracking behavior in children. Neuropsychopharmacology. 2018;43(1):228-9. https://doi.org/ 10.1038/npp.2017.196.

124. Colaizzi JM, Flagel SB, Joyner MA, Gearhardt AN, Stewart JL, Paulus MP. Mapping sign-tracking and goal-tracking onto human behaviors. Neurosci Biobehav Rev. 2020;111:84-94. https://doi. org/10.1016/j.neubiorev.2020.01.018.

125. Radell ML, Myers CE, Beck KD, Moustafa AA, Allen MT. The personality trait of intolerance to uncertainty affects behavior in a novel computer-based conditioned place preference task. Front Psychol. 2016;7(1175). https://doi.org/10.3389/fpsyg.2016. 01175.

126. Astur RS, Carew AW, Deaton BE. Conditioned place preferences in humans using virtual reality. Behav Brain Res. 2014;267:1737. https://doi.org/10.1016/j.bbr.2014.03.018.

127. Astur RS, Palmisano AN, Carew AW, Deaton BE, Kuhney FS, Niezrecki RN, et al. Conditioned place preferences in humans using secondary reinforcers. Behav Brain Res. 2016;297:15-9. https://doi.org/10.1016/j.bbr.2015.09.042.

128. Childs E, Astur RS, de Wit H. Virtual reality conditioned place preference using monetary reward. Behav Brain Res. 2017;322(Part A):110-4. https://doi.org/10.1016/j.bbr.2017.01. 019.

129. Molet M, Billiet G, Bardo MT. Conditioned place preference and aversion for music in a virtual reality environment. Behav Process. 2013;92:31-5. https://doi.org/10.1016/j.beproc.2012.10.001.

130. Childs E, de Wit H. Amphetamine-induced place preference in humans. Biol Psychiatry. 2009;65(10):900-4. https://doi.org/10. 1016/j.biopsych.2008.11.016.

131. Childs E, de Wit H. Contextual conditioning enhances the psychostimulant and incentive properties of d-amphetamine in humans. Addict Biol. 2013;18(6):985-92. https://doi.org/10. 1111/j.1369-1600.2011.00416.x.

132. Takahashi YK, Roesch MR, Stalnaker TA, Haney RZ, Calu DJ, Taylor AR, et al. The orbitofrontal cortex and ventral tegmental area are necessary for learning from unexpected outcomes. Neuron. 2009;62(2):269-80. https://doi.org/10.1016/j.neuron. 2009.03.005.

133. Blaiss CA, Janak PH. The nucleus accumbens core and shell are critical for the expression, but not the consolidation, of Pavlovian conditioned approach. Behav Brain Res. 2009;200(1):22-32. https://doi.org/10.1016/j.bbr.2008.12.024. 
134. Baunez C, Dias C, Cador M, Amalric M. The subthalamic nucleus exerts opposite control on cocaine and 'natural' rewards. Nat Neurosci. 2005;8(4):484-9. https://doi.org/10.1038/nn1429.

135. Haney RZ, Calu DJ, Takahashi YK, Hughes BW, Schoenbaum G. Inactivation of the central but not the basolateral nucleus of the amygdala disrupts learning in response to overexpectation of reward. J Neurosci. 2010;30(8):2911-7. https://doi.org/10.1523/ jneurosci.0054-10.2010

136. Maren S, Quirk GJ. Neuronal signaling of fear memory. Nat Rev Neurosci. 2004;5(11):844-52. https://doi.org/10.1038/nrn1535.

137. Murray EA. The amygdala, reward and emotion. Trends Cogn Sci. 2007;11(11):489-97. https://doi.org/10.1016/j.tics.2007.08. 013.

138. Nasser HM, Lafferty DS, Lesser EN, Bacharach SZ, Calu DJ. Disconnection of basolateral amygdala and insular cortex disrupts conditioned approach in Pavlovian lever autoshaping. Neurobiol Learn Mem. 2018;147:35-45. https://doi.org/10.1016/j.nlm.2017. 11.010 .

139. Ferbinteanu J, McDonald RJ. Dorsal/ventral hippocampus, fornix, and conditioned place preference. Hippocampus. 2001;11(2):187200. https://doi.org/10.1002/hipo.1036.

140. McIntyre CK, Ragozzino ME, Gold PE. Intra-amygdala infusions of scopolamine impair performance on a conditioned place preference task but not a spatial radial maze task. Behav Brain Res. 1998;95(2):219-26. https://doi.org/10.1016/s0166-4328(97) 00161-7.

141. Peters J, Kalivas PW, Quirk GJ. Extinction circuits for fear and addiction overlap in prefrontal cortex. Learn Mem. 2009;16:27988. https://doi.org/10.1101/lm.1041309.

142. Quirk GJ, Mueller D. Neural mechanisms of extinction learning and retrieval. Neuropsychopharmacology. 2008;33:56-72. https:// doi.org/10.1038/sj.npp.1301555.

143. Bacharach SZ, Nasser HM, Zlebnik NE, Dantrassy HM, Kochli DE, Gyawali U, et al. Cannabinoid receptor-1 signaling contributions to sign-tracking and conditioned reinforcement in rats. Psychopharmacology. 2018;235(10):3031-43. https://doi.org/10. 1007/s00213-018-4993-6.

144. Oleson Erik B, Beckert Michael V, Morra Joshua T, Lansink Carien S, Cachope R, Abdullah Rehab A, et al. Endocannabinoids shape accumbal encoding of cue-motivated behavior via CB1 receptor activation in the ventral tegmentum. Neuron. 2012;73(2):360-73. https://doi.org/10.1016/j.neuron. 2011.11.018.

145. Pasquariello KZ, Han M, Unal C, Meyer PJ. Adrenergic manipulation inhibits Pavlovian conditioned approach behaviors. Behav Brain Res. 2018;339:278-85. https://doi.org/10.1016/j.bbr.2017. 10.037 .

146. Lee JLC, Everitt BJ. Reactivation-dependent amnesia in Pavlovian approach and instrumental transfer. Learn Mem. 2008;15(8):597-602. https://doi.org/10.1101/lm.1029808.

147. Schultz W, Dayan P, Montague PR. A neural substrate of prediction and reward. Science. 1997;275(5306):1593-9. https://doi.org/ 10.1126/science. 275.5306 .1593

148. Schultz W. Predictive reward signal of dopamine neurons. J Neurophysiol. 1998;80(1):1-27. https://doi.org/10.1152/jn.1998. 80.1.1.

149. Flagel SB, Clark JJ, Robinson TE, Mayo L, Czuj A, Willuhn I, et al. A selective role for dopamine in stimulus-reward learning. Nature. 2011;469(7328):53-7. https://doi.org/10.1038/ nature09588.

150. Saunders BT, Robinson TE. The role of dopamine in the accumbens core in the expression of Pavlovian-conditioned responses. Eur J Neurosci. 2012;36(4):2521-32. https://doi.org/10.1111/j. 1460-9568.2012.08217.x

151. Lesaint F, Sigaud O, Flagel SB, Robinson TE, Khamassi M. Modeling individual differences in the form of Pavlovian conditioned approach responses: a dual learning systems approach with factored representations. PLoS Comput Biol. 2014;10(2): E1003466. https://doi.org/10.1371/journal.pcbi.1003466.

152. Lee B, Gentry RN, Bissonette GB, Herman RJ, Mallon JJ, Bryden $\mathrm{DW}$, et al. Manipulating the revision of reward value during the intertrial interval increases sign tracking and dopamine release. PLoS Biol. 2018;16(9):E2004015. https://doi.org/10.1371/ journal.pbio.2004015.

153. Lesaint F, Sigaud O, Clark JJ, Flagel SB, Khamassi M. Experimental predictions drawn from a computational model of sign-trackers and goal-trackers. J Physiol Paris. 2015;109(1):7886. https://doi.org/10.1016/j.jphysparis.2014.06.001.

154. Cinotti F, Marchand AR, Roesch MR, Girard B, Khamassi M. Impacts of inter-trial interval duration on a computational model of sign-tracking vs. goal-tracking behavior. Psychopharmacology. 2019;236(8):2373-88. https://doi.org/10.1007/s00213-01905323-y.

155. Martin-Soelch C, Linthicum J, Ernst M. Appetitive conditioning: neural bases and implications for psychopathology. Neurosci Biobehav Rev. 2007;31(3):426-40. https://doi.org/10.1016/j. neubiorev.2006.11.002

156. O’Doherty JP, Deichmann R, Critchley HD, Dolan RJ. Neural responses during anticipation of a primary taste reward. Neuron. 2002;33(5):815-26. https://doi.org/10.1016/s0896-6273(02) 00603-7.

157. Tapia León I, Kruse O, Stalder T, Stark R, Klucken T. Neural correlates of subjective CS/UCS association in appetitive conditioning. Hum Brain Mapp. 2018;39(4):1637-46. https://doi.org/ 10.1002/hbm.23940.

158. Kahnt T, Heinzle J, Park SQ, Haynes J-D. Decoding the formation of reward predictions across learning. J Neurosci. 2011;31(41): 14624-30. https://doi.org/10.1523/jneurosci.3412-11.2011.

159. Metereau E, Dreher J-C. Cerebral correlates of salient prediction error for different rewards and punishments. Cereb Cortex. 2013;23(2):477-87. https://doi.org/10.1093/cercor/bhs037.

160. Pauli WM, Gentile G, Collette S, Tyszka JM, O'Doherty JP. Evidence for model-based encoding of Pavlovian contingencies in the human brain. Nat Commun. 2019;10(1):1099. https://doi. org/10.1038/s41467-019-08922-7.

161. Takemura H, Samejima K, Vogels R, Sakagami M, Okuda J. Stimulus-dependent adjustment of reward prediction error in the midbrain. PLoS ONE. 2011;6(12):E28337. https://doi.org/10. 1371/journal.pone.0028337.

162. Bray S, O'Doherty JP. Neural coding of reward-prediction error signals during classical conditioning with attractive faces. J Neurophysiol. 2007;97(4):3036-45. https://doi.org/10.1152/jn. 01211.2006

163. Chase HW, Kumar P, Eickhoff SB, Dombrovski AY. Reinforcement learning models and their neural correlates: an activation likelihood estimation meta-analysis. Cogn Affect Behav Ne. 2015;15(2):435-59. https://doi.org/10.3758/s13415015-0338-7.

164. Goode TD, Maren S. Common neurocircuitry mediating drug and fear relapse in preclinical models. Psychopharmacology. 2019;236:415-37. https://doi.org/10.1007/s00213-018-5024-3.

165. Konova AB, Goldstein RZ. The emerging neuroscience of appetitive and drug cue extinction in humans. Psychopharmacology. 2019;236(1):407-14. https://doi.org/10.1007/s00213-018-5098$\mathrm{y}$.

166. Konova AB, Parvaz MA, Bernstein V, Zilverstand A, Moeller SJ, Delgado MR, et al. Neural mechanisms of extinguishing drug and pleasant cue associations in human addiction: role of the VMPFC. Addict Biol. 2019;24(1):88-99. https://doi.org/10.1111/adb. 12545 .

167. Ebrahimi C, Koch SP, Friedel E, Crespo I, Fydrich T, Ströhle A, et al. Combining D-cycloserine with appetitive extinction learning 
modulates amygdala activity during recall. Neurobiol Learn Mem. 2017;142:209-17. https://doi.org/10.1016/j.nlm.2017.05.008.

168. Kruse O, Tapia León I, Stark R, Klucken T. Neural correlates of appetitive extinction in humans. Soc Cogn Affect Neurosci. 2017;12(1):106-15. https://doi.org/10.1093/scan/nsw157.

169. Zhang Z, Mendelsohn A, Manson KF, Schiller D, Levy I. Dissociating value representation and inhibition of inappropriate affective response during reversal learning in the ventromedial prefrontal cortex. eNeuro. 2016;2(6). https://doi.org/10.1523/ eneuro.0072-15.2015.

170. Howard JD, Kahnt T, Gottfried JA. Converging prefrontal pathways support associative and perceptual features of conditioned stimuli. Nat Commun. 2016;7(1):11546. https://doi.org/10.1038/ ncomms 11546

171. Kahnt T, Park SQ, Haynes J-D, Tobler PN. Disentangling neural representations of value and salience in the human brain. Proc Natl Acad Sci U S A. 2014;111(13):5000-5. https://doi.org/10.1073/ pnas. 1320189111.

172. O'Doherty JP, Dayan P, Friston KJ, Critchley H, Dolan RJ. Temporal difference models and reward-related learning in the human brain. Neuron. 2003;38(2):329-37. https://doi.org/10. 1016/s0896-6273(03)00169-7.

173. Prévost C, McNamee D, Jessup RK, Bossaerts P, O’Doherty JP. Evidence for model-based computations in the human amygdala during Pavlovian conditioning. PLoS Comput Biol. 2013;9(2): E1002918. https://doi.org/10.1371/journal.pcbi.1002918.

174. Krank MD. Pavlovian conditioning with ethanol: sign-tracking (autoshaping), conditioned incentive, and ethanol self-administration. Alcohol Clin Exp Res. 2003;27(10):1592-8. https://doi.org/ 10.1097/01.alc.0000092060.09228.de.

175. Tomie A, Festa ED, Sparta DR, Pohorecky LA. Lever conditioned stimulus-directed autoshaping induced by saccharin-ethanol unconditioned stimulus solution: effects of ethanol concentration and trial spacing. Alcohol. 2003;30(1):35-44. https://doi.org/10.1016/ s0741-8329(03)00069-7.

176. Villaruel FR, Chaudhri N. Individual differences in the attribution of incentive salience to a Pavlovian alcohol cue. Front Behav Neurosci. 2016;10(238). https://doi.org/10.3389/fnbeh.2016. 00238.

177. Srey CS, Maddux J-MN, Chaudhri N. The attribution of incentive salience to Pavlovian alcohol cues: a shift from goal-tracking to sign-tracking. Front Behav Neurosci. 2015;9(54). https://doi.org/ 10.3389/fnbeh.2015.00054.

178. Fiorenza AM, Shnitko TA, Sullivan KM, Vemuru SR, Gomez-A A, Esaki JY, et al. Ethanol exposure history and alcoholic reward differentially alter dopamine release in the nucleus accumbens to a reward-predictive cue. Alcohol Clin Exp Res. 2018;42(6):105161. https://doi.org/10.1111/acer.13636.

179. Krank MD, O’Neill S, Squarey K, Jacob J. Goal- and signaldirected incentive: conditioned approach, seeking, and consumption established with unsweetened alcohol in rats. Psychopharmacology. 2008;196(3):397-405. https://doi.org/10. 1007/s00213-007-0971-0.

180. Madayag AC, Stringfield SJ, Reissner KJ, Boettiger CA, Robinson DL. Sex and adolescent ethanol exposure influence Pavlovian conditioned approach. Alcohol Clin Exp Res. 2017;41(4):846-56. https://doi.org/10.1111/acer.13354.

181. McClory AJ, Spear LP. Effects of ethanol exposure during adolescence or in adulthood on Pavlovian conditioned approach in Sprague-Dawley rats. Alcohol. 2014;48(8):755-63. https://doi. org/10.1016/j.alcohol.2014.05.006.

182. Spoelder M, Tsutsui KT, Lesscher HMB, Vanderschuren LJMJ, Clark JJ. Adolescent alcohol exposure amplifies the incentive value of reward-predictive cues through potentiation of phasic dopamine signaling. Neuropsychopharmacology. 2015;40(13):287385. https://doi.org/10.1038/npp.2015.139.
183. Ciccocioppo R, Panocka I, Froldi R, Quitadamo E, Massi M. Ethanol induces conditioned place preference in genetically selected alcohol-preferring rats. Psychopharmacology. 1999;141(3):235-41. https://doi.org/10.1007/s002130050830.

184. Cunningham CL, Prather LK. Conditioning trial duration affects ethanol-induced conditioned place preference in mice. Anim Learn Behav. 1992;20:187-94. https://doi.org/10.3758/ bf03200416.

185. Gremel CM, Cunningham CL. Involvement of amygdala dopamine and nucleus accumbens NMDA receptors in ethanol-seeking behavior in mice. Neuropsychopharmacology. 2009;34(6):144353. https://doi.org/10.1038/npp.2008.179.

186. Bahi A. Increased anxiety, voluntary alcohol consumption and ethanol-induced place preference in mice following chronic psychosocial stress. Stress. 2013;16(4):441-51. https://doi.org/10. 3109/10253890.2012.754419.

187. Leichtweis KS, Carvalho M, Morais-Silva G, Marin MT, Amaral VCS. Short and prolonged maternal separation impacts on ethanol-related behaviors in rats: sex and age differences. Stress. 2020;23(2):162-73. https://doi.org/10.1080/10253890.2019. 1653847.

188. Yu L, Wang L, Zhao X, Song M, Wang X. Role of single prolonged stress in acquisition of alcohol conditioned place preference in rats. Life Sci. 2016;151:259-63. https://doi.org/10.1016/ j.lfs.2016.03.004.

189. Kuzmin A, Sandin J, Terenius L, Ögren SO. Acquisition, expression, and reinstatement of ethanol-induced conditioned place preference in mice: effects of opioid receptor-like 1 receptor agonists and naloxone. J Pharmacol Exp Ther. 2003;304(1):310-8. https:// doi.org/10.1124/jpet.102.041350.

190. Houchi H, Babovic D, Pierrefiche O, Ledent C, Daoust M, Naassila $\mathrm{M} . \mathrm{CB}_{1}$ receptor knockout mice display reduced ethanol-induced conditioned place preference and increased striatal dopamine $\mathrm{D}_{2}$ receptors. Neuropsychopharmacology. 2005;30(2):339-49. https://doi.org/10.1038/sj.npp.1300568.

191. Thanos PK, Dimitrakakis ES, Rice O, Gifford A, Volkow ND. Ethanol self-administration and ethanol conditioned place preference are reduced in mice lacking cannabinoid CB1 receptors. Behav Brain Res. 2005;164(2):206-13. https://doi.org/10.1016/j. bbr.2005.06.021

192. Ventura R, Carolis DD, Alcaro A, Puglisi-Allegra S. Ethanol consumption and reward depend on norepinephrine in the prefrontal cortex. Neuroreport. 2006;17(17):1813-7. https://doi.org/10. 1097/01.wnr.0000239964.83566.75.

193. Gremel CM, Cunningham CL. Roles of the nucleus accumbens and amygdala in the acquisition and expression of ethanolconditioned behavior in mice. J Neurosci. 2008;28(5):1076-84. https://doi.org/10.1523/jneurosci.4520-07.2008.

194. Groblewski PA, Lattal KM, Cunningham CL. Effects of Dcycloserine on extinction and reconditioning of ethanol-seeking behavior in mice. Alcohol Clin Exp Res. 2009;33(5):772-82. https://doi.org/10.1111/j.1530-0277.2009.00895.x.

195. Font L, Houck CA, Cunningham CL. Naloxone effects on extinction of ethanol- and cocaine-induced conditioned place preference in mice. Psychopharmacology. 2017;234(18):2747-59. https:// doi.org/10.1007/s00213-017-4672-z.

196. Cunningham CL, Henderson CM, Bormann NM. Extinction of ethanol-induced conditioned place preference and conditioned place aversion: effects of naloxone. Psychopharmacology. 1998;139(1):62-70. https://doi.org/10.1007/s002130050690.

197. Bie B, Zhu W, Pan ZZ. Ethanol-induced delta-opioid receptor modulation of glutamate synaptic transmission and conditioned place preference in central amygdala. Neuroscience. 2009;160(2):348-58. https://doi.org/10.1016/j.neuroscience. 2009.02.049. 
198. Cunningham CL, Patel P. Rapid induction of Pavlovian approach to an ethanol-paired visual cue in mice. Psychopharmacology. 2007;192(2):231-41. https://doi.org/10.1007/s00213-007-07044.

199. Dandaba M, Serra W, Harika-Germaneau G, Silvain C, Langbour N, Solinas M, et al. Predicting relapse in patients with severe alcohol use disorder: the role of alcohol insight and implicit alcohol associations. Addict Behav. 2020;107:106433. https://doi.org/ 10.1016/j.addbeh.2020.106433.

200. Wiers CE, Gladwin TE, Ludwig VU, Gröpper S, Stuke H, Gawron CK, et al. Comparing three cognitive biases for alcohol cues in alcohol dependence. Alcohol Alcohol. 2017;52(2):242-8. https://doi.org/10.1093/alcalc/agw063.

201. Wiers CE, Stelzel C, Park SQ, Gawron CK, Ludwig VU, Gutwinski S, et al. Neural correlates of alcohol-approach bias in alcohol addiction: the spirit is willing but the flesh is weak for spirits. Neuropsychopharmacology. 2014;39:688-97. https://doi. org/10.1038/npp.2013.252.

202. Ryan F. Attentional bias and alcohol dependence: a controlled study using the modified Stroop paradigm. Addict Behav. 2002;27(4):471-82. https://doi.org/10.1016/s0306-4603(01) 00183-6.

203. Garland EL, Franken IH, Sheetz JJ, Howard MO. Alcohol attentional bias is associated with autonomic indices of stress-primed alcohol cue-reactivity in alcohol-dependent patients. Exp Clin Psychopharmacol. 2012;20(3):225-35. https://doi.org/10.1037/ a0027199.

204. Vollstädt-Klein S, Loeber S, Richter A, Kirsch M, Bach P, von der Goltz $\mathrm{C}$, et al. Validating incentive salience with functional magnetic resonance imaging: association between mesolimbic cue reactivity and attentional bias in alcohol-dependent patients. Addict Biol. 2012;17(4):807-16. https://doi.org/10.1111/j.1369-1600. 2011.00352.x.

205. Cox WM, Hogan LM, Kristian MR, Race JH. Alcohol attentional bias as a predictor of alcohol abusers' treatment outcome. Drug Alcohol Depend. 2002;68(3):237-43. https://doi.org/10.1016/ S0376-8716(02)00219-3.

206. Garland EL, Franken IHA, Howard MO. Cue-elicited heart rate variability and attentional bias predict alcohol relapse following treatment. Psychopharmacology. 2012;222:17-26. https://doi.org/ 10.1007/s00213-011-2618-4.

207. Seo D, Lacadie CM, Tuit K, Hong KI, Todd Constable R, Sinha R. Disrupted ventromedial prefrontal function, alcohol craving, and subsequent relapse risk. JAMA Psychiatry. 2013;70(7):72739. https://doi.org/10.1001/jamapsychiatry.2013.762.

208. Kreusch F, Billieux J, Quertemont E. Alcohol-cue exposure decreases response inhibition towards alcohol-related stimuli in detoxified alcohol-dependent patients. Psychiatry Res. 2017;249: 232-9. https://doi.org/10.1016/j.psychres.2017.01.019.

209. Witteman J, Post H, Tarvainen M, de Bruijn A, Perna EDSF, Ramaekers JG, et al. Cue reactivity and its relation to craving and relapse in alcohol dependence: a combined laboratory and field study. Psychopharmacology. 2015;232(20):3685-96. https://doi.org/10.1007/s00213-015-4027-6.

210. Papachristou H, Nederkoorn C, Havermans R, Bongers P, Beunen $\mathrm{S}$, Jansen A. Higher levels of trait impulsiveness and a less effective response inhibition are linked to more intense cue-elicited craving for alcohol in alcohol-dependent patients. Psychopharmacology. 2013;228(4):641-9. https://doi.org/10. 1007/s00213-013-3063-3.

211. Papachristou H, Nederkoorn C, Giesen JCAH, Jansen A. Cue reactivity during treatment, and not impulsivity, predicts an initial lapse after treatment in alcohol use disorders. Addict Behav. 2014;39(3):737-9. https://doi.org/10.1016/j.addbeh.2013.11.027.

212. Sjoerds Z, van den Brink W, Beekman ATF, Penninx BWJH, Veltman DJ. Cue reactivity is associated with duration and severity of alcohol dependence: an fMRI study. PLoS ONE. 2014;9(1):e84560. https://doi.org/10.1371/journal.pone.0084560.

213. Rohsenow DJ, Monti PM, Rubonis AV, Sirota AD, Niaura RS, Colby SM, et al. Cue reactivity as a predictor of drinking among male alcoholics. J Consult Clin Psychol. 1994;62(3):620-6. https://doi.org/10.1037/0022-006x.62.3.620.

214. Eddie D, Buckman JF, Mun EY, Vaschillo B, Vaschillo E, Udo T, et al. Different associations of alcohol cue reactivity with negative alcohol expectancies in mandated and inpatient samples of young adults. Addict Behav. 2013;38(4):2040-3. https://doi.org/10. 1016/j.addbeh.2013.01.006.

215. Kvamme TL, Pedersen MU, Overgaard M, Rømer Thomsen K, Voon V. Pupillary reactivity to alcohol cues as a predictive biomarker of alcohol relapse following treatment in a pilot study. Psychopharmacology. 2019;236(4):1233-43. https://doi.org/10. 1007/s00213-018-5131-1.

216. Braus DF, Wrase J, Grüsser S, Hermann D, Ruf M, Flor H, et al. Alcohol-associated stimuli activate the ventral striatum in abstinent alcoholics. J Neural Transm. 2001;108(7):887-94. https:// doi.org/10.1007/s007020170038.

217. Heinz A, Siessmeier T, Wrase J, Hermann D, Klein S, GrüsserSinopoli SM, et al. Correlation between dopamine $\mathrm{D}_{2}$ receptors in the ventral striatum and central processing of alcohol cues and craving. Am J Psychiatry. 2004;161(10):1783-9. https://doi.org/ 10.1176/ajp.161.10.1783.

218. Grüsser SM, Wrase J, Klein S, Hermann D, Smolka MN, Ruf M, et al. Cue-induced activation of the striatum and medial prefrontal cortex is associated with subsequent relapse in abstinent alcoholics. Psychopharmacology. 2004;175:296-302. https://doi.org/ 10.1007/s00213-004-1828-4.

219. Reinhard I, Leménager T, Fauth-Bühler M, Hermann D, Hoffmann S, Heinz A, et al. A comparison of region-of-interest measures for extracting whole brain data using survival analysis in alcoholism as an example. J Neurosci Methods. 2015;242:58 64. https://doi.org/10.1016/j.jneumeth.2015.01.001.

220. Beck A, Wüstenberg T, Genauck A, Wrase J, Schlagenhauf F, Smolka MN, et al. Effect of brain structure, brain function, and brain connectivity on relapse in alcohol-dependent patients. Arch Gen Psychiatry. 2012;69(8):842-52. https://doi.org/10.1001/ archgenpsychiatry.2011.2026.

221. Fukushima S, Kuga H, Oribe N, Mutou T, Yuzuriha T, Ozawa H, et al. Behavioral cue reactivity to alcohol-related and non-alcoholrelated stimuli among individuals with alcohol use disorder: an fMRI study with a visual task. PLoS ONE. 2020;15(7): E0229187. https://doi.org/10.1371/journal.pone.0229187.

222. Schacht JP, Anton RF, Myrick H. Functional neuroimaging studies of alcohol cue reactivity: a quantitative meta-analysis and systematic review. Addict Biol. 2013;18(1):121-33. https://doi.org/ 10.1111/j.1369-1600.2012.00464.x.

223. Roy-Charland A, Plamondon A, Homeniuk AS, Flesch CA, Klein RM, Stewart SH. Attentional bias towards alcohol-related stimuli in heavy drinkers: evidence from dynamic eye movement recording. Am J Drug Alcohol Abuse. 2017;43(3):332-40. https://doi. org/10.1080/00952990.2016.1209511.

224. Pennington CR, Shaw DJ, Adams J, Kavanagh P, Reed H, Robinson M, et al. Where's the wine? Heavy social drinkers show attentional bias towards alcohol in a visual conjunction search task. Addiction. 2020;115(9):1650-9. https://doi.org/10.1111/ add.14997.

225. Wang W, Zhornitsky S, Le TM, Zhang S, Li CSR. Heart rate variability, cue-evoked ventromedial prefrontal cortical response, and problem alcohol use in adult drinkers. Biol Psychiatry. 2020;5(6):619-28. https://doi.org/10.1016/j.bpsc.2019.12.013.

226. Field M, Eastwood B. Experimental manipulation of attentional bias increases the motivation to drink alcohol. 
Psychopharmacology. 2005;183(3):350-7. https://doi.org/10. 1007/s00213-005-0202-5.

227. Papachristou H, Nederkoorn C, Havermans R, van der Horst M, Jansen A. Cannot stop the craving: the effect of impulsivity on cue-elicited craving for alcohol in heavy and light social drinkers. Psychopharmacology. 2012;219(2):511-8. https://doi.org/10. 1007/s00213-011-2240-5.

228. Kaag AM, Wiers RW, de Vries TJ, Pattij T, Goudriaan AE. Striatal alcohol cue-reactivity is stronger in male than female problem drinkers. Eur J Neurosci. 2019;50(3):2264-73. https://doi. org/10.1111/ejn.13991.

229. Filbey FM, Claus E, Audette AR, Niculescu M, Banich MT, Tanabe J, et al. Exposure to the taste of alcohol elicits activation of the mesocorticolimbic neurocircuitry. Neuropsychopharmacology. 2008;33(6):1391-401. https://doi. org/10.1038/sj.npp.1301513

230. Vollstädt-Klein S, Wichert S, Rabinstein J, Bühler M, Klein O, Ende G, et al. Initial, habitual and compulsive alcohol use is characterized by a shift of cue processing from ventral to dorsal striatum. Addiction. 2010;105(10):1741-9. https://doi.org/10.1111/j. 1360-0443.2010.03022.x.

231. Ihssen N, Cox WM, Wiggett A, Fadardi JS, Linden DEJ. Differentiating heavy from light drinkers by neural responses to visual alcohol cues and other motivational stimuli. Cereb Cortex. 2011;21(6):1408-15. https://doi.org/10.1093/cercor/bhq220.

232. Childs E, de Wit H. Alcohol-induced place conditioning in moderate social drinkers. Addiction. 2016;111(12):2157-2165. https://doi.org/10.1111/add.13540. This work translated the conditioned place preference paradigm to humans, showing that behavioral preference for alcohol-paired locations can be induced experimentally.

233. Glautier S, Drummond C, Remington B. Alcohol as an unconditioned stimulus in human classical conditioning. Psychopharmacology. 1994;116(3):360-8. https://doi.org/10. 1007/bf02245341.

234. Mayo LM, de Wit H. Acquisition of conditioned responses to a novel alcohol-paired cue in social drinkers. J Stud Alcohol Drugs. 2016;77(2):317-26. https://doi.org/10.15288/jsad.2016.77.317.

235. Oberlin BG, Dzemidzic M, Eiler WJA, Carron CR, Soeurt CM, Plawecki MH, et al. Pairing neutral cues with alcohol intoxication: new findings in executive and attention networks. Psychopharmacology. 2018;235:2725-37. https://doi.org/10. 1007/s00213-018-4968-7.

236. Field M, Duka T. Cues paired with a low dose of alcohol acquire conditioned incentive properties in social drinkers. Psychopharmacology. 2002;159(3):325-34. https://doi.org/10. 1007/s00213-001-0923-z.

237. Cartoni E, Balleine BW, Baldassarre G. Appetitive Pavlovianinstrumental transfer: a review. Neurosci Biobehav Rev. 2016;71:829-48. https://doi.org/10.1016/j.neubiorev.2016.09. 020 .

238. Geurts DEM, Huys QJM, den Ouden HEM, Cools R. Aversive Pavlovian control of instrumental behavior in humans. J Cogn Neurosci. 2013;25(9):1428-41. https://doi.org/10.1162/jocn_a_ 00425.

239. Cartoni E, Puglisi-Allegra S, Baldassarre G. The three principles of action: a Pavlovian-instrumental transfer hypothesis. Front Behav Neurosci. 2013;7:153. https://doi.org/10.3389/fnbeh. 2013.00153.

240. Corbit LH, Janak PH. Ethanol-associated cues produce general Pavlovian-instrumental transfer. Alcohol Clin Exp Res. 2007;31(5):766-74. https://doi.org/10.1111/j.1530-0277.2007. 00359.x.

241. Corbit LH, Janak PH, Balleine BW. General and outcome-specific forms of Pavlovian-instrumental transfer: the effect of shifts in motivational state and inactivation of the ventral tegmental area.
Eur J Neurosci. 2007;26(11):3141-9. https://doi.org/10.1111/j. 1460-9568.2007.05934.x.

242. Corbit LH, Balleine BW. Double dissociation of basolateral and central amygdala lesions on the general and outcome-specific forms of Pavlovian-instrumental transfer. J Neurosci. 2005;25(4):962-70. https://doi.org/10.1523/jneurosci.4507-04. 2005.

243. Dickinson A, Balleine BW. The role of learning in the operation of motivational systems. In: Gallistel R, editor. Stevens' Handbook of Experimental Psychology. 3rd ed. New York: Wiley; 2002. p. 497-534.

244. Balleine BW, Ostlund SB. Still at the choice-point. Ann N Y Acad Sci. 2007;1104(1):147-71. https://doi.org/10.1196/annals.1390. 006.

245. Hogarth L, Retzler C, Munafò MR, Tran DMD, Troisi JR II, Rose AK, et al. Extinction of cue-evoked drug-seeking relies on degrading hierarchical instrumental expectancies. Behav Res Ther. 2014;59:61-70. https://doi.org/10.1016/j.brat.2014.06.001.

246. Hogarth L, Balleine BW, Corbit LH, Killcross S. Associative learning mechanisms underpinning the transition from recreational drug use to addiction. Ann N Y Acad Sci. 2013;1282(1):12-24. https://doi.org/10.1111/j.1749-6632.2012.06768.x.

247. Hogarth L, Troisi JR II. A hierarchical instrumental decision theory of nicotine dependence. In: Balfour DJK, Munafò MR, editors. The neurobiology and genetics of nicotine and tobacco. Cham: Springer International Publishing; 2015. p. 165-91.

248. Prévost C, Liljeholm M, Tyszka JM, O'Doherty JP. Neural correlates of specific and general Pavlovian-to-instrumental transfer within human amygdalar subregions: a high-resolution fMRI study. J Neurosci. 2012;32(24):8383-90. https://doi.org/10.1523/ jneurosci.6237-11.2012.

249. Watson P, Wiers RW, Hommel B, de Wit S. Working for food you do not desire. Cues interfere with goal-directed food-seeking. Appetite. 2014;79:139-48. https://doi.org/10.1016/j.appet.2014. 04.005 .

250. Nadler N, Delgado MR, Delamater AR. Pavlovian to instrumental transfer of control in a human learning task. Emotion. 2011;11(5): 1112-23. https://doi.org/10.1037/a0022760.

251. Huys QJM, Cools R, Gölzer M, Friedel E, Heinz A, Dolan RJ, et al. Disentangling the roles of approach, activation and valence in instrumental and Pavlovian responding. PLoS Comput Biol. 2011;7(4):E1002028. https://doi.org/10.1371/journal.pcbi. 1002028.

252. Lovibond PF, Colagiuri B. Facilitation of voluntary goal-directed action by reward cues. Psychol Sci. 2013;24(10):2030-7. https:// doi.org/10.1177/0956797613484043.

253. De Tommaso M, Mastropasqua T, Turatto M. Working for beverages without being thirsty: human Pavlovian-instrumental transfer despite outcome devaluation. Learn Motiv. 2018;63:37-48. https://doi.org/10.1016/j.lmot.2018.01.001.

254. Aitken TJ, Greenfield VY, Wassum KM. Nucleus accumbens core dopamine signaling tracks the need-based motivational value of food-paired cues. J Neurochem. 2016;136(5):1026-36. https:// doi.org/10.1111/jnc. 13494 .

255. Bezzina L, Lee JC, Lovibond PF, Colagiuri B. Extinction and renewal of cue-elicited reward-seeking. Behav Res Ther. 2016;87:162-9. https://doi.org/10.1016/j.brat.2016.09.009.

256. Garofalo S, Battaglia S, di Pellegrino G. Individual differences in working memory capacity and cue-guided behavior in humans. Sci Rep. 2019;9:7327. https://doi.org/10.1038/s41598-01943,860-w.

257. Wassum KM, Ostlund SB, Balleine BW, Maidment NT. Differential dependence of Pavlovian incentive motivation and instrumental incentive learning processes on dopamine signaling. Learn Mem. 2011;18(7):475-83. https://doi.org/10.1101/lm. 2229311. 
258. Wassum KM, Ostlund SB, Loewinger GC, Maidment NT. Phasic mesolimbic dopamine release tracks reward seeking during expression of Pavlovian-to-instrumental transfer. Biol Psychiatry. 2013;73(8):747-55. https://doi.org/10.1016/j.biopsych.2012.12. 005 .

259. Lex A, Hauber W. Dopamine $\mathrm{D}_{1}$ and $\mathrm{D}_{2}$ receptors in the nucleus accumbens core and shell mediate Pavlovian-instrumental transfer. Learn Mem. 2008;15(7):483-91. https://doi.org/10.1101/lm. 978708 .

260. Cardinal RN, Everitt BJ. Neural and psychological mechanisms underlying appetitive learning: links to drug addiction. Curr Opin Neurobiol. 2004;14(2):156-62. https://doi.org/10.1016/j.conb. 2004.03.004.

261. Ostlund SB, Liu AT, Wassum KM, Maidment NT. Modulation of cue-triggered reward seeking by cholinergic signaling in the dorsomedial striatum. Eur J Neurosci. 2017;45(3):358-64. https://doi.org/10.1111/ejn.13462.

262. Collins AL, Aitken TJ, Huang IW, Shieh C, Greenfield VY, Monbouquette HG, et al. Nucleus accumbens cholinergic interneurons oppose cue-motivated behavior. Biol Psychiatry. 2019;86(5):388-96. https://doi.org/10.1016/j.biopsych.2019.02. 014.

263. Ostlund SB, Kosheleff AR, Maidment NT. Differential effects of systemic cholinergic receptor blockade on Pavlovian incentive motivation and goal-directed action selection. Neuropsychopharmacology. 2014;39(6):1490-7. https://doi.org/ 10.1038/npp.2013.348.

264. Collins AL, Aitken TJ, Greenfield VY, Ostlund SB, Wassum KM. Nucleus accumbens acetylcholine receptors modulate dopamine and motivation. Neuropsychopharmacology. 2016;41(12):2830 8. https://doi.org/10.1038/npp.2016.81.

265. Corbit LH, Balleine BW. The general and outcome-specific forms of Pavlovian-instrumental transfer are differentially mediated by the nucleus accumbens core and shell. J Neurosci. 2011;31(33): 11786-94. https://doi.org/10.1523/jneurosci.2711-11.2011.

266. Hall J, Parkinson JA, Connor TM, Dickinson A, Everitt BJ. Involvement of the central nucleus of the amygdala and nucleus accumbens core in mediating Pavlovian influences on instrumental behavior. Eur J Neurosci. 2001;13(10):1984-92. https://doi. org/10.1046/j.0953-816x.2001.01577.x

267. Holland PC, Gallagher M. Double dissociation of the effects of lesions of basolateral and central amygdala on conditioned stimulus-potentiated feeding and Pavlovian-instrumental transfer. Eur J Neurosci. 2003;17(8):1680-94. https://doi.org/10.1046/j. 1460-9568.2003.02585.x.

268. Corbit LH, Muir JL, Balleine BW. The role of the nucleus accumbens in instrumental conditioning: evidence of a functional dissociation between accumbens core and shell. J Neurosci. 2001;21(9):3251-60. https://doi.org/10.1523/jneurosci.21-0903251.2001.

269. Blundell P, Hall G, Killcross S. Lesions of the basolateral amygdala disrupt selective aspects of reinforcer representation in rats. J Neurosci. 2001;21(22):9018-26. https://doi.org/10.1523/ jneurosci.21-22-09018.2001.

270. Shiflett MW, Balleine BW. At the limbic-motor interface: disconnection of basolateral amygdala from nucleus accumbens core and shell reveals dissociable components of incentive motivation. Eur J Neurosci. 2010;32(10):1735-43. https://doi.org/10.1111/j.14609568.2010.07439.x.

271. Leung BK, Balleine BW. Ventral pallidal projections to mediodorsal thalamus and ventral tegmental area play distinct roles in outcome-specific Pavlovian-instrumental transfer. J Neurosci. 2015;35(12):4953-1964. https://doi.org/10.1523/ jneurosci.4837-14.2015.

272. Corbit LH, Janak PH. Inactivation of the lateral but not medial dorsal striatum eliminates the excitatory impact of Pavlovian stimuli on instrumental responding. J Neurosci. 2007;27(51): 13977-81. https://doi.org/10.1523/jneurosci.4097-07.2007.

273. Keistler C, Barker JM, Taylor JR. Infralimbic prefrontal cortex interacts with nucleus accumbens shell to unmask expression of outcome-selective Pavlovian-to-instrumental transfer. Learn Mem. 2015;22(10):509-13. https://doi.org/10.1101/lm.038810. 115.

274. Homayoun H, Moghaddam B. Differential representation of Pavlovian-instrumental transfer by prefrontal cortex subregions and striatum. Eur J Neurosci. 2009;29(7):1461-76. https://doi. org/10.1111/j.1460-9568.2009.06679.x.

275. Ostlund SB, Balleine BW. Orbitofrontal cortex mediates outcome encoding in Pavlovian but not instrumental conditioning. J Neurosci. 2007;27(18):4819-25. https://doi.org/10.1523/ jneurosci.5443-06.2007.

276. Leung BK, Balleine BW. The ventral striato-pallidal pathway mediates the effect of predictive learning on choice between goaldirected actions. J Neurosci. 2013;33(34):13848-60. https://doi. org/10.1523/jneurosci.1697-13.2013.

277. Lichtenberg NT, Pennington ZT, Holley SM, Greenfield VY, Cepeda C, Levine MS, et al. Basolateral amygdala to orbitofrontal cortex projections enable cue-triggered reward expectations. J Neurosci. 2017;37(35):8374-84. https://doi.org/10.1523/ jneurosci.0486-17.2017.

278. Bray S, Rangel A, Shimojo S, Balleine BW, O'Doherty JP. The neural mechanisms underlying the influence of Pavlovian cues on human decision making. J Neurosci. 2008;28(22):5861-6. https:// doi.org/10.1523/jneurosci.0897-08.2008.

279. Lewis AH, Niznikiewicz MA, Delamater AR, Delgado MR. Avoidance-based human Pavlovian-to-instrumental transfer. Eur J Neurosci. 2013;38(12):3740-8. https://doi.org/10.1111/ejn. 12377 .

280. Mendelsohn A, Pine A, Schiller D. Between thoughts and actions: motivationally salient cues invigorate mental action in the human brain. Neuron. 2014;81(1):207-17. https://doi.org/10.1016/j. neuron.2013.10.019.

281. Talmi D, Seymour B, Dayan P, Dolan RJ. Human Pavlovianinstrumental transfer. J Neurosci. 2008;28(2):360-8. https://doi. org/10.1523/jneurosci.4028-07.2008.

282. Hebart MN, Gläscher J. Serotonin and dopamine differentially affect appetitive and aversive general Pavlovian-to-instrumental transfer. Psychopharmacology. 2015;232(2):437-51. https://doi. org/10.1007/s00213-014-3682-3.

283. Weber SC, Beck-Schimmer B, Kajdi ME, Muller D, Tobler PN, Quednow BB. Dopamine $\mathrm{D}_{2 / 3}$ - and $\mu$-opioid receptor antagonists reduce cue-induced responding and reward impulsivity in humans. Transl Psychiatry. 2016;6:E850. https://doi.org/10.1038/tp.2016. 113.

284. Corbit LH, Janak PH. Changes in the influence of alcohol-paired stimuli on alcohol seeking across extended training. Front Psychiatry. 2016;7(169). https://doi.org/10.3389/fpsyt.2016. 00169.

285. Corbit LH, Fischbach SC, Janak PH. Nucleus accumbens core and shell are differentially involved in general and outcome-specific forms of Pavlovian-instrumental transfer with alcohol and sucrose rewards. Eur J Neurosci. 2016;43(9):1229-36. https://doi.org/10. 1111/ejn.13235.

286. Glasner SV, Overmier JB, Balleine BW. The role of Pavlovian cues in alcohol seeking in dependent and nondependent rats. J Stud Alcohol. 2005;66(1):53-61. https://doi.org/10.15288/jsa. 2005.66.53.

287. Alarcón DE, Delamater AR. Outcome-specific Pavlovian-toinstrumental transfer (PIT) with alcohol cues and its extinction. Alcohol. 2019;76:131-46. https://doi.org/10.1016/j.alcohol.2018. 09.003 . 
288. Lamb RJ, Ginsburg BC, Schindler CW. Effects of an ethanolpaired CS on responding for ethanol and food: comparisons with a stimulus in a truly-random-control group and to a food-paired CS on responding for food. Alcohol. 2016;57:15-27. https://doi. org/10.1016/j.alcohol.2016.10.009.

289. Milton AL, Schramm MJW, Wawrzynski JR, Gore F, Oikonomou-Mpegeti F, Wang NQ, et al. Antagonism at NMDA receptors, but not $\beta$-adrenergic receptors, disrupts the reconsolidation of Pavlovian conditioned approach and instrumental transfer for ethanol-associated conditioned stimuli. Psychopharmacology. 2012;219(3):751-61. https://doi.org/10. 1007/s00213-011-2399-9.

290. Garbusow M, Schad DJ, Sommer C, Jünger E, Sebold M, Friedel E, et al. Pavlovian-to-instrumental transfer in alcohol dependence: a pilot study. Neuropsychobiology. 2014;70(2):111-21. https:// doi.org/10.1159/000363507.

291. Garbusow M, Schad DJ, Sebold M, Friedel E, Bernhardt N, Koch SP, et al. Pavlovian-to-instrumental transfer effects in the nucleus accumbens relate to relapse in alcohol dependence. Addict Biol. 2016;21(3):719-31. https://doi.org/10.1111/adb.12243.

292. Sommer C, Garbusow M, Junger E, Pooseh S, Bernhardt N, Birkenstock J, et al. Strong seduction: impulsivity and the impact of contextual cues on instrumental behavior in alcohol dependence. Transl Psychiatry. 2017;7:E1183. https://doi.org/10.1038/ tp.2017.158.

293. Sommer C, Birkenstock J, Garbusow M, Obst E, Schad DJ, Bernhardt N, et al. Dysfunctional approach behavior triggered by alcohol-unrelated Pavlovian cues predicts long-term relapse in alcohol dependence. Addict Biol. 2020;25(1):E12703. https:// doi.org/10.1111/adb.12703.

294. Garbusow M, Nebe S, Sommer C, Kuitunen-Paul S, Sebold M, Schad DJ, et al. Pavlovian-to-instrumental transfer and alcohol consumption in young male social drinkers: behavioral, neural and polygenic correlates. J Clin Med. 2019;8(8):1188. https:// doi.org/10.3390/jcm 8081188 This study demonstrated that the PIT effect was stronger in high-compared to low-risk drinkers and associated it with polygenic risk for alcohol consumption.

295. Schad DJ, Garbusow M, Friedel E, Sommer C, Sebold M, Hägele $\mathrm{C}$, et al. Neural correlates of instrumental responding in the context of alcohol-related cues index disorder severity and relapse risk. Eur Arch Psychiatry Clin Neurosci. 2019;269(3):295-308. https://doi.org/10.1007/s00406-017-0860-4.

296. Sekutowicz M, Guggenmos M, Kuitunen-Paul S, Garbusow M, Sebold M, Pelz P, et al. Neural response patterns during Pavlovian-to-instrumental transfer predict alcohol relapse and young adult drinking. Biol Psychiatry. 2019;86(11):857-63. https://doi.org/10.1016/j.biopsych.2019.06.028 This work showed that machine learning approaches can be used to predict alcohol relapse in AUD participants based on neuronal activation patterns during a PIT task.

297. Hogarth L, Lam-Cassettari C, Pacitti H, Currah T, Mahlberg J, Hartley L, et al. Intact goal-directed control in treatment-seeking drug users indexed by outcome-devaluation and Pavlovian to instrumental transfer: critique of habit theory. Eur J Neurosci. 2019;50(3):2513-25. https://doi.org/10.1111/ejn.13961.

298. Hardy L, Mitchell C, Seabrooke T, Hogarth L. Drug cue reactivity involves hierarchical instrumental learning: evidence from a biconditional Pavlovian to instrumental transfer task. Psychopharmacology. 2017;234(13):1977-84. https://doi.org/10. 1007/s00213-017-4605-x.

299. Martinovic J, Jones A, Christiansen P, Rose AK, Hogarth L, Field M. Electrophysiological responses to alcohol cues are not associated with Pavlovian-to-instrumental transfer in social drinkers. PLoS ONE. 2014;9(4):E94605. https://doi.org/10.1371/journal. pone.0094605.
300. Rose AK, Brown K, MacKillop J, Field M, Hogarth L. Alcohol devaluation has dissociable effects on distinct components of alcohol behavior. Psychopharmacology. 2018;235(4):1233-44. https://doi.org/10.1007/s00213-018-4839-2.

301. Dickinson A, Balleine BW, Watt A, Gonzalez F, Boakes RA. Motivational control after extended instrumental training. Anim Learn Behav. 1995;23(2):197-206. https://doi.org/10.3758/ bf03199935.

302. de Wit S, Kindt M, Knot SL, Verhoeven AAC, Robbins TW, Gasull-Camos J, et al. Shifting the balance between goals and habits: five failures in experimental habit induction. J Exp Psychol Gen. 2018;147(7):1043-65. https://doi.org/10.1037/ xge0000402.

303. Hardwick RM, Forrence AD, Krakauer JW, Haith AM. Timedependent competition between goal-directed and habitual response preparation. Nat Hum Behav. 2019;3:1252-62. https:// doi.org/10.1038/s41562-019-0725-0.

304. Ceceli AO, Tricomi E. Habits and goals: a motivational perspective on action control. Curr Opin Behav Sci. 2018;20:110-6. https://doi.org/10.1016/j.cobeha.2017.12.005.

305. Wiers CE, Stelzel C, Gladwin TE, Park SQ, Pawelczack S, Gawron CK, et al. Effects of cognitive bias modification training on neural alcohol cue reactivity in alcohol dependence. Am J Psychiatry. 2015;172(4):335-43. https://doi.org/10.1176/appi. ajp.2014.13111495.

306. Wiers RW, Eberl C, Rinck M, Becker ES, Lindenmeyer J. Retraining automatic action tendencies changes alcoholic patients' approach bias for alcohol and improves treatment outcome. Psychol Sci. 2011;22(4):490-7. https://doi.org/10.1177/ 0956797611400615.

307. Wiers RW, Rinck M, Kordts R, Houben K, Strack F. Retraining automatic action-tendencies to approach alcohol in hazardous drinkers. Addiction. 2010;105(2):279-87. https://doi.org/10. 1111/j.1360-0443.2009.02775.x.

308. Kiefer F, Kirsch M, Bach P, Hoffmann S, Reinhard I, Jorde A, et al. Effects of D-cycloserine on extinction of mesolimbic cue reactivity in alcoholism: a randomized placebo-controlled trial. Psychopharmacology. 2015;232:2353-62. https://doi.org/10. 1007/s00213-015-3882-5.

309. MacKillop J, Few LR, Stojek MK, Murphy CM, Malutinok SF, Johnson FT, et al. D-cycloserine to enhance extinction of cueelicited craving for alcohol: a translational approach. Transl Psychiatry. 2015;5:E544. https://doi.org/10.1038/tp.2015.41.

310. Das RK, Gale G, Hennessy V, Kamboj SK. A prediction errordriven retrieval procedure for destabilizing and rewriting maladaptive reward memories in hazardous drinkers. J Vis Exp. 2018;131: E56097. https://doi.org/10.3791/56097.

311. Das RK, Lawn W, Kamboj SK. Rewriting the valuation and salience of alcohol-related stimuli via memory reconsolidation. Transl Psychiatry. 2015;5:E645. https://doi.org/10.1038/tp.2015. 132.

312. Hon T, Das RK, Kamboj SK. The effects of cognitive reappraisal following retrieval-procedures designed to destabilize alcohol memories in high-risk drinkers. Psychopharmacology. 2016;233: 851-61. https://doi.org/10.1007/s00213-015-4164-y.

313. Heinz A, Kiefer F, Smolka MN, Endrass T, Beste C, Beck A, et al. Addiction Research Consortium: losing and regaining control over drug intake (ReCoDe) - from trajectories to mechanisms and interventions. Addict Biol. 2020;25(2):E12866. https://doi. org/10.1111/adb.12866.

Publisher's Note Springer Nature remains neutral with regard to jurisdictional claims in published maps and institutional affiliations. 